NBER WORKING PAPER SERIES

THE VALUE OF STOCK OPTIONS TO NON-EXECUTIVE EMPLOYEES

\author{
Kevin F. Hallock \\ Craig A. Olson \\ Working Paper 11950 \\ http://www.nber.org/papers/w11950 \\ NATIONAL BUREAU OF ECONOMIC RESEARCH \\ 1050 Massachusetts Avenue \\ Cambridge, MA 02138 \\ January 2006
}

We are grateful to Joe Altonji, Mike Boozer, Jim Brickley, David Card, Ken Chay, Todd Elder, Hank Farber, Tom Lemieux, Darren Lubotsky, Jim Rebitzer, Bill Schwert, Larry Van Horn, Charles Wasley, Gerard Wedig, Jerry Zimmerman, and seminar participants at Berkeley, Case Western, Illinois at Chicago, Illinois at Urbana-Champaign, Minnesota, Rochester, Wisconsin- Milwaukee, Yale, and the 2005 SOLE Meetings, San Francisco for helpful suggestions. We also thank the Center for Human Resource Management at the University of Illinois for their financial support and officials at the company that supplied the data used in this analysis and carefully described their stock option program. Hallock is Associate Professor of Human Resource Studies at the ILR School, Cornell University. Olson is the ILIR Alumni Professor at the Institute of Labor \& Industrial Relations at the University of Illinois at Urbana/Champaign. Most of the work on this paper was completed when Hallock was at the University of Illinois. Authorship was determined alphabetically. The views expressed herein are those of the author(s) and do not necessarily reflect the views of the National Bureau of Economic Research.

(C2006 by Kevin F. Hallock and Craig A. Olson. All rights reserved. Short sections of text, not to exceed two paragraphs, may be quoted without explicit permission provided that full credit, including $\odot$ notice, is given to the source. 
The Value of Stock Options to Non-Executive Employees

Kevin F. Hallock and Craig A. Olson

NBER Working Paper No. 11950

January 2006

JEL No. J3, G3

\begin{abstract}
This study empirically investigates the value employees place on stock options using information from the option exercise behavior of individuals. Employees hold options for another period if the value from holding them and reserving the right to exercise them later is higher than the value of exercising them immediately and collecting a profit equal to the stock price minus the exercise price. This simple model implies the hazard describing employee exercise behavior reveals information about the value to employees of holding options another time period. We show the parameters of this model are identified with data on multiple option grants per employee and we apply this model to the disposition of options received in the 1990s by a sample of over 2000 middle-level managers from a large, established firm outside of manufacturing. Exercise behavior is modeled using a random effects probit model of monthly exercise behavior that is estimated using simulated maximum likelihood estimation methods. Our estimates show there is substantial heterogeneity (observed and unobserved) among employees in the value they place on their options. Our estimates show most employees value their options at a value greater than the option's Black-Scholes value. Kevin F. Hallock

School of Industrial and Labor Relations

Cornell University

387A Ives Hall

Ithaca, NY 14850

and NBER

kfh7@cornell.edu

Craig A. Olson

Institute of Labor and Industrial Relations

University of Illinois at Urbana-Champaign

217 LIR Building

Champaign, IL 61820

caolson@uiuc.edu
\end{abstract}




\section{The Value of Stock Options to Non-Executive Employees}

Over the past 20 years there has been dramatic growth in the use of stock options for senior-level executives (e.g. Hall and Leibman, 1998 and Murphy, 1999) and by the mid-1990s substantial growth in the use of options for non-executive employees had begun that has recently been dampened due to a number of factors including the market adjustment of 2001 and changes in Financial Accounting Standards Board (FASB) rules. Using Black-Scholes to value options, stock options to managers and employees who are not among the top 5 highest paid employees in the firm grew from less than 85 percent of total options granted to employees in the mid-1990s to over 90 percent by 2002 (Hall and Murphy, 2003). A variety of explanations have been offered for the growth in employee stock options including providing incentives to employees, motivating employees to sort, employee retention, and financing constraints (Bergman and Jenter, 2005, Core and Guay, 2001, Kedia and Mozumdar, 2002, Lazear, 2003, and Oyer and Schaefer, 2005a,b).

Understanding the specific reasons for the use of employee stock options by firms requires knowledge of the costs and benefits to both firms and employees of options relative to cash or other forms of compensation. Because the payoff to an employee from stock options depends on the firm's stock price which is beyond the complete control of even the most senior manager, option based compensation exposes risk averse employees to uncertainty that they must be compensated for to make them indifferent between an option and cash compensation costing the firm an equal amount. Economically rational explanations for the use of stock options require that the risk premium a firm pays to employees to accept options instead of cash is offset by the benefits the firm expects to receive from granting the options. These benefits from options may be reflected in lower agency costs, lower turnover, increased commitment by workers to the firm, etc. ${ }^{1}$

Understanding where firms use stock options requires estimates of both the dollar value employees place on options and the magnitude of the benefits firms receive by granting stock options to

\footnotetext{
${ }^{1}$ We do not investigate some potentially important tax issues in this paper.
} 
employees. In this study we take a step toward making this evaluation by empirically estimating the value a sample of middle managers place on the stock options they received from their employer. Previous research emphasizes the distinction between the cost of options to firms and the likely lower value employees place on options due to employee risk aversion and the characteristics of employee stock option grants (Lambert, Larcker, and Verecchia, 1991, and Hall and Murphy, 2000, 2002, 2003). However, this research has not produced an estimate of the value employees place on options inferred from the observed behavior of a sample of option holders. Hall and Murphy (2002) calculate the value executives place on options by making assumptions about the form of an executive's utility function, their level of risk aversion and the share of their wealth invested in their firm's stock. While this research provides valuable insight into the possible trade-offs between options and cash compensation, their calculations are a function of the assumptions they make about executives and are not directly inferred from the behavior of a sample of employees who have received options.

In this study we empirically estimate the dollar value employees place on employee stock options (ESO) at a particular time for a particular set of employees using a method that requires few assumptions about the form of the utility function or the level of employee risk aversion. Our method generalizes to any other situation where employees are given options. Our analysis is based on the observation that an employee will choose to hold an option for another period (e.g. day, week, or month) if the utility of the income she would receive (e.g. stock price - exercise price) by immediately exercising the option is less than the value from holding the option and reserving the right to exercise it on a later date. Conversely, if she exercises in the current period, then we know the value from not exercising the option is less than what she gains now by exercising the option and receiving an amount equal to the stock price minus the exercise price. Our model implies the decision to exercise or hold an option for another period provides the critical piece of information needed to infer the value employees place on an option at any point in time when the option could be exercised for a profit (e.g., stock price - exercise price $>0$ ).

The rest of the paper is organized as follows. In section I we introduce the theoretical model used to estimate the value employees place on options. Section II discusses model identification and 
estimation methods. The data are described in Section III and Section IV presents the results. Section V examines the late exercise activity by employees from one option grant using a simple analysis that is consistent with the more elaborate model presented in Sections I-IV. Section VI summarizes our research and discusses the implications of our findings for additional research and the current public policy debate regulating the information firms are required to disclose about the cost of employee stock options.

\section{A Model of Employee Exercise Decisions}

Like virtually all previous discussions of the value of stock options to employees, the starting point for this research is the pioneering work of Black and Scholes (1973) and Merton (1973) who describe how rational investors holding a diversified portfolio value tradable stock options. The famous diagram shown in Figure 1 summarizes the basic relationship between the Black-Scholes value (BSV) of a call option and the firm's stock price and the option's exercise price. The Black-Scholes model assumes stock returns each period are normally and independently distributed so the expected stock price on the expiration date of the option is greater than the exercise price described by the mean of a truncated log normal distribution truncated at the exercise price. Mathematically, the Black-Scholes value (BSV) of the option in Figure 1 at any current stock price is equal to the expected value of $\mathrm{E}\left[\mathrm{Max}\left(\left(\mathrm{SP}_{\mathrm{T}}-\mathrm{EP}\right), 0\right)\right]$ discounted from the expiration time $\mathrm{T}$ to the present at the risk free interest rate. They show the value of

holding an option is a function of six variables- the risk free interest rate, the expiration date of the option, the variance in the firm's stock returns, the firm's dividend rate, the option exercise price and the current stock price. The BSV declines or shifts in toward the kinked intrinsic value line (e.g., $\left.\operatorname{Max}\left(\left(\mathrm{SP}_{\mathrm{t}}-\mathrm{EP}\right), 0\right)\right)$ as the option expiration date approaches, the firm's dividend rate increases, the risk free interest rate increases or the variance in the firm's stock returns declines.

The Black-Scholes model predicts that a diversified investor will never exercise an American call option prior to the moment before it expires because at any earlier date the expected gain from holding the option until the expiration date is greater than the intrinsic value of the option. In other words, the possibility of a stock price increase between now and the expiration date makes the Black-Scholes value 
greater than the profit that could be made by immediately exercising the option and receiving the option's intrinsic value, $\left(\mathrm{SP}_{\mathrm{t}}-\mathrm{EP}\right)$. It is important to note that the model makes no prediction about how long an individual investor will own a market traded option. The model only predicts that prior to the expiration date an investor will sell the option rather than exercise an option to increase liquidity or rebalance his portfolio.

Applying Black-Scholes to ESO is thought to give a poor estimate of the value of the option to an employee who receives it as part of her compensation package. The empirical evidence cited to support this conclusion is that employees frequently exercise ESO "early" or well before the option's expiration date (Huddart and Lang, 1996; Carpenter 1998). In the firm we study 86 percent of employees exercised their options prior to the month before the options expired and half of the sample exercised some of their options at least 27 months prior to their expiration. ${ }^{2}$ In a simulation study, Hall \& Murphy (2002) show risk averse executives who also have a substantial portion of their portfolio invested in the firm may exercise "early" to lock-in gains from large stock price increases and diversify their portfolio. Heath, Huddart and Lang (1999) find that employees tend to exercise options when the firm's stock price exceeds a target or referent price based on recent stock price highs. Since an employee must typically forfeit her options if she leaves the firm, early exercise decisions may also be caused by voluntary or involuntary employee turnover (Carpenter 1998).

The observation that employees frequently exercise ESOs "early" compared to the Black-Scholes prediction for market traded options reflects the fact that employees cannot sell the options they receive from their employer and must exercise the options if they wish to liquidate their position to diversify their portfolio, meet a budget constraint or prepare for an anticipated departure from the firm. This fundamental feature of ESOs is the basis for our model because it implies valuable information about the option's value to an employee is revealed each period by observing whether or not a vested option is exercised. If an option is not exercised in a period then a researcher can conclude the value to the employee of holding the option and reserving the right to exercise it in a later period is greater than the

\footnotetext{
${ }^{2}$ These data are for the first large ESO grant awards made to the middle level managers included in this study.
} 
value of exercising the option and receiving the option's intrinsic value. On the other hand, if an employee exercises an option in a period, then the observer knows the value of holding the option another period is less than what is gained by exercising the option and receiving a payment equal to the stock price minus the exercise price. Thus, the decision to exercise or hold an option for another period is an indicator of the value an employee places on an option at a point in time. Therefore, the exercise hazard rate for an option grant to a firm's employees reveals information about employee heterogeneity in the value they place on the options.

Formally, define the following terms: $\mathrm{SP}_{\mathrm{t}}=$ stock price at time " $\mathrm{t}$ " where " $\mathrm{t}$ " indexes the time since the option vested, $\mathrm{EP}_{\mathrm{k}, \mathrm{j}}=$ exercise price for option " $\mathrm{k}$ " granted to employee " $\mathrm{j}$ " , $\mathrm{EVF}_{\mathrm{k}, \mathrm{j}, \mathrm{t}}=\mathrm{Employee}$ Value Function (EVF) or the utility (in dollars) to person "j" in period "t" from holding option "k" another time period. For vested options held by an employee, in each period " $t$ " we assume the employee decides whether to hold the option another period or to exercise the option by comparing the utility from exercising the option with the utility of holding the option for another period. Since $\mathrm{SP}_{t}-\mathrm{EP}_{\mathrm{k}, \mathrm{j}}$ equals the certain cash payment the employee receives from exercising the option, the option will be exercised if this cash payment is greater than the monetary value to the employee of holding the option another period:

(1a) $\left(S P_{t}-E P_{k, j}\right)>E V F_{k, j, t}$

and the option will be held another period if

(1b) $\left(S P_{t}-E P_{k, j}\right) \leq E V F_{k, j, t}$.

Let $\mathrm{EVF}_{\mathrm{k}, \mathrm{j}, \mathrm{t}}$ be a linear function of a set of observable characteristics of the employee, the option and the market $(\mathrm{X})$ and an unobserved randomly distributed error term that is indexed by option grant, person and time:

(2) $E V F_{k, j, t}=X_{k, j, t} \beta+v_{k, j, t}$, where $v \sim \mathrm{N}\left(0, \sigma^{2}{ }_{\mathrm{v}}\right)$.

Equations (1) and (2) describe the probability an option will be exercised in period "t" conditional on the exogenous variables. Let $\mathrm{I}_{\mathrm{k}, \mathrm{j}, \mathrm{t}}=1$ if option " $\mathrm{k}$ " held by employee " $\mathrm{j}$ ” is exercised in period " $\mathrm{t}$ ", and zero otherwise. The probability $I_{k, j, t}=1$ is: 
(3a) $\operatorname{Pr}\left(I_{k, j, t}=1\right)=\operatorname{Pr}\left(\left(S P_{t}-E P_{k, j}\right)>E V F_{k, j, t}\right)$

(3b) $\operatorname{Pr}\left(I_{k, j, t}=1\right)=\operatorname{Pr}\left[\left(S P_{t}-E P_{k, j}\right)>X_{k, j, t} \beta+v_{k, j, t}\right]$

(3c) $\left.\operatorname{Pr}\left(I_{k, j, t}=1\right)=\operatorname{Pr}\left[v_{k, j, t}<\left(S P_{t}-E P_{k, j}\right)-X_{k, j, t} \beta\right)\right]$

(3d) $\left.\operatorname{Pr}\left(I_{k, j, t}=1\right)=\Phi\left[\left(\left(S P_{t}-E P_{k, j}\right)-X_{k, j, t} \beta\right)\right) / \sigma_{v}\right]$,

where $\Phi($.$) is the CDF for a standard normal variable.$

The right hand side of equation (3d) shows the probability an option is exercised in period $t$ depends on the difference between the value from exercising the option immediately $\left(\mathrm{SP}_{\mathrm{t}}-\mathrm{EP}_{\mathrm{k}, \mathrm{j}}\right)$ and holding the option for another period. This is shown in Figure 2. The probability the option is exercised is the shaded area or the probability that $v_{k, j, t}$ is sufficiently small to cause EVF to be less than SP-EP.

For model identification and estimation reasons that are explored in the next section, the error term in the preceding model is assumed to be normally distributed. This assumption implies the value to an employee of holding an option another period could assume either very "large" or "small" values that are inconsistent with previous predictions made about the value employees place on options. As noted earlier, previous research (e.g. Lambert, Larcker, and Verecchia, 1991) has assumed the value of an option to an employee is less than the option's Black-Scholes value because of the design of employee stock option plans and the risk aversion of employees. Employees receiving stock options are likely to be "over-invested" in their firm relative to an outside investor because they cannot sell the options and are heavily invested in the firm through firm specific human capital and implicit or explicit deferred compensation (pensions) that depend on the success and survival of the firm. This lack of diversification and the possibility of having to exercise "early" because of turnover risk leads to the prediction that employees value options at less than their BSV. One way of imposing the constraint that EVF $<$ BSV in the empirical analysis is to let the $\mathrm{X}$ variables equal just a single variable, the option's BSV, and constrain the coefficient on this variable to be less than one.

While there are strong theoretical reasons to believe economically rational employees will value their options at less than their BSV, in practice employees may have great difficulty using Black-Scholes 
as a benchmark in their personal valuations because of the limited information employees have about the option market and option valuation theory. These judgments are difficult because there is no market information that employees can use to aid their valuation because the 10 year term of a typical ESO is far longer than market traded options that may exist for the firm. Employees also have no way of determining the value an outside investor or lender would place on the option since employees cannot sell their options or use them as collateral for a loan. Without market information, it is unlikely the typical employee will be knowledgeable about option pricing theory or able to solve an option pricing problem that won a Nobel Prize in economics for Merton and Scholes. Therefore, we estimate an unconstrained model using Eq 2 and 3 a where EVF is an unconstrained function of BSV, $\mathrm{BSV}^{2}$ and $\mathrm{BSV}^{3}$, a constrained model where the coefficient on BSV is constrained to be less than one and a "truncated model" described in the next paragraph ${ }^{3}$

The one piece of market information employees do observe when making their exercise decisions is the firm's stock price. Standard results in finance show any rational model employees use provides an option value less than the firm's stock price because an employee is always better off owning the share of stock when given the choice between an option and share of stock each priced at SP (Brealey, Myers \& Marcus 1995). If $\mathrm{SP} \leq \mathrm{EP}$ on the expiration date the option is worth nothing but the share of stock is still worth SP $>0$. If SP $>$ EP the share of stock is also worth more than the option as the option is worth SPEP and the share of stock is worth SP. Thus, a rational employee will never value an option at more than the stock's current price. This fact is used to specify a truncated model where EVF cannot exceed the firm's stock price. The distribution of EVF when truncated at SP is

(4a) $E V F_{k, j, t}=X_{j, t} C+v_{j, t}$

(4b) $\mathrm{f}\left(v \mid \mathrm{EVF}_{\mathrm{k}, \mathrm{j}, \mathrm{t}}<\mathrm{SP}_{\mathrm{t}}\right)=\left(1 / \sigma_{v}\right) \mathrm{f}\left(\left(\mathrm{EVF}_{\mathrm{k}, \mathrm{j}, \mathrm{t}}-\mathrm{X}_{\mathrm{j}, \mathrm{t}} \mathrm{C}\right) / \sigma_{v}\right) \Phi\left(\left(\mathrm{SP}_{\mathrm{t}}-\mathrm{X}_{\mathrm{j}, \mathrm{t}} \mathrm{C}\right) / \sigma_{v}\right)$

The probability an option is exercised in period $\mathrm{t}$ conditional on (SP-EP) and $\mathrm{X}$ is:

\footnotetext{
${ }^{3}$ The constrained model was estimated by letting the coefficient on BSV equal $1 /\left(1+\exp \left(\beta_{\mathrm{BSV}}\right)\right)$.
} 
(5) $\operatorname{Pr}\left(E V F_{k, j, t}<\left(S P_{t}-E P_{k, j}\right)\right)=\Phi\left(\frac{\left(S P_{t}-E P_{k, j}\right)}{\sigma_{v}}-X_{j, t} \frac{C}{\sigma_{v}}\right) / \Phi\left(\frac{S P_{t}}{\sigma_{v}}-X_{j, t} \frac{C}{\sigma_{v}}\right)$.

and the probability an option is not exercised in period $t$ is $\operatorname{Pr}\left(\mathrm{EVF}_{\mathrm{k}, \mathrm{j}, \mathrm{t}}>\left(\mathrm{SP}_{\mathrm{t}}-\mathrm{EP}_{\mathrm{k}, \mathrm{j}}\right)\right)$. We refer to this

model as the truncated model. In summary, we estimate three basic theoretical models; one model (" $\beta_{\mathrm{BSV}}$ $<1$ model") where the coefficient on an option's BSV in the employee value function is constrained to be less than one, a second model that constrains the employee value function to be less than the firm's stock price ("truncated model") and a third model that imposes neither of these constraints ("unconstrained model"). Our preferred model is the truncated model because it is theoretically supported but still flexible enough to allow the data to test whether the EVF is greater or less than an option's BSV.

\section{Model Identification and Other Econometric Issues}

In the models developed above exercise decisions each period are based on whether or not the EVF is greater or less than a threshold value equal to the option's intrinsic value, (SP-EP). In the typical study where the dependent variable is a discrete, binary outcome, only the standardized coefficients, $\beta / \sigma$, are identified in the probit model because the threshold determining which outcome is observed is unobserved and arbitrarily set to zero. While the standardized coefficients are sufficient to predict exercise decisions, inferring the dollar value of an option from exercise behavior requires estimates of the unstandardized coefficients, the Cs and $\sigma_{v}$. Because the exercise decision is based on the value of EVF relative to an observed threshold (SP-EP), the unstandardized coefficients are identified in the probit model if options data have different exercise prices.

A natural way to parameterize the EVF is to make it a function of the Black-Scholes value of the option because it reflects rational expectations about the value of the option on its expiration date to a diversified investor, or:

(6) $E V F_{k, j, t}=\alpha\left(B S V_{k, t}\right)+v_{k, j, t}$

In this specification the probability an option is exercised in period t equals: 
(7) $\operatorname{Pr}\left(E V F_{k, j, t}<\left(S P_{t}-E P_{k, j}\right)\right)=\Phi\left(\frac{\left(S P_{t}-E P_{k, j}\right)}{\sigma_{v}}-\frac{\alpha}{\sigma_{v}} B S V_{k, t}\right)$

This equation shows $\alpha$ and $\sigma_{\mathrm{v}}$ are separately identified if (SP-EP) varies in the data because the parameter on (SP-EP) equals $1 / \sigma_{\mathrm{v}}$ and the parameter on BSV equals $\alpha / \sigma_{\mathrm{v}}$. Alternatively, if all the options in the dataset have the same exercise price then in any period " $\mathrm{t}$ " (SP-EP) is a constant, making $\sigma_{\mathrm{v}}$ unidentified which, in turn, means $\alpha$ is unidentified and only the standardized coefficient on BSV, $\alpha / \sigma_{\mathrm{v}}$, can be estimated. ${ }^{4}$ Thus, option data with multiple exercise prices is required to estimate the "structural" parameters of the EVF described by Equation (1).

In most ESO plans the exercise price and expiration date for options granted to employees on a specific date are identical for all employees. The exercise price is typically set equal to the firm's stock price on the grant date and the options expire on the same day 6-10 years later. Exercise data with only one grant and expiration date creates a second identification problem for Eq. (7). If the dataset includes options that have the same exercise price and expiration date, then all the options have the same BlackScholes value in any period. Thus, even if (SP-EP) were excluded from the probit equation the relationship between EVF and the option's EVF could not be estimated without variation in the time remaining until the options expire. We overcome this identification problem by using data on options granted to a common group of employees on multiple dates. Since all of the options in our sample expire 10 years from their grant dates, the time left until the options expire produces different Black-Scholes values on day " $\mathrm{t}$ " and identifies how exercise decisions are affected by difference in the Black-Scholes value of an option. To summarize, it is possible with data on grants with different exercise prices and expiration dates to identify the EVF in period " $\mathrm{t}$ " and permit the EVF to be a function of the BlackScholes value of the option in period " $t$ " using only information on whether or not options are exercised in period " $\mathrm{t}$ ".

\footnotetext{
${ }^{4}$ There are other settings where researchers have been able to identify $\sigma$ in a probit model. For example, empirical studies of the fair wage beliefs of arbitrations under final offer arbitration identify $\sigma$ from variation in the final offers presented to arbitrators. See Ashenfelter \& Bloom (1984) and Olson \& Jarley (1991).
} 
We now sketch a slightly more formal proof of how $\alpha$ and $\sigma_{v}$ in Eq. (7) are identified using exercise activity in period $t$ for options that have different exercise prices and expiration dates. Assume a firm provides one option to each employee under two option grant plans - plan "A" and "B". Options in the two plans are granted on two different dates, at different exercise prices and all options expire after 10 years. In period "t" when the options are "above water" (e.g., SP>EP), data are collected on the fraction of unexercised options that are exercised in period " $t$ " from each option plan. Thus, we have the following data: $\left(\mathrm{SP}_{\mathrm{t}}-\mathrm{EP}_{\mathrm{A}}\right),\left(\mathrm{SP}_{\mathrm{t}}-\mathrm{EP}_{\mathrm{B}}\right), \mathrm{BS}_{\mathrm{A}}, \mathrm{BS}_{\mathrm{B}}, \mathrm{P}_{\mathrm{A}}$ and $\mathrm{P}_{\mathrm{B}}$ where $\mathrm{P}_{\mathrm{k}}$ is the fraction of unexercised options from grant $\mathrm{k}$ exercised in period t. Equation (7) shows the relationships between these variables is described by the following two equations:

$$
P_{A}=\Phi\left(\frac{\left(S P_{t}-E P_{A}\right)}{\sigma_{v}}-\frac{\alpha}{\sigma_{v}} B S_{A}\right) \text { and } P_{B}=\Phi\left(\frac{\left(S P_{t}-E P_{B}\right)}{\sigma_{v}}-\frac{\alpha}{\sigma_{v}} B S_{B}\right) \text {. }
$$

The two unknown parameters, $\alpha$ and $\sigma_{\mathrm{v}}$, can be solved from these two equations.

The constraint in the truncated model that the EVF is less than the firm's stock price provides an additional source of identification for $\sigma_{\mathrm{v}}$ that is not part of the other two models. The preceding discussion shows that $\sigma_{v}$ is identified in the unconstrained model from two option grants based on differences in the probabilities $\left(\mathrm{P}_{\mathrm{A}}\right.$ and $\left.\mathrm{P}_{\mathrm{B}}\right)$ the EVFs are less than the options' intrinsic values and the shape of the lower tail of the normally distributed error term, $v$, below (Intrinsic Value) $)_{\mathrm{A}}$ and (Intrinsic Value $)_{B}$. As the variance in $v$ increases, $\mathrm{P}_{\mathrm{A}}$ and $\mathrm{P}_{\mathrm{B}}$ increase by different quantities because of the nonlinearities in the normal distribution. In the truncated model identification of $\sigma_{\mathrm{v}}$ is helped further by the constraint that EVF is less than the stock price. Equation (5) shows the probability an option is exercised is a function both the $\operatorname{Pr}(\mathrm{EVF}<\mathrm{EP})$ and $\operatorname{Pr}(\mathrm{EVF}<\mathrm{SP})$. The exercise probability increases as $\sigma_{\mathrm{v}}$ increases because the numerator $(\operatorname{Pr}(\mathrm{EVF}<\mathrm{EP}))$ increases and because the denominator $(\operatorname{Pr}(\mathrm{EVF}<\mathrm{SP}))$ declines. The truncated model shown in Figure 3 describes two options that have different exercise prices. This figure shows the exercise probability for each option is a function of both $\operatorname{Pr}(\mathrm{EVF}<\mathrm{EP})$ and $\operatorname{Pr}(\mathrm{EVF}<\mathrm{SP})$; option A has a greater probability of being exercised even though $\operatorname{Pr}(\mathrm{EVF}<\mathrm{EP})_{\mathrm{A}}$ and $\operatorname{Pr}(\mathrm{EVF}<\mathrm{EP})_{\mathrm{B}}$ are approximately equal because $\operatorname{Pr}(\mathrm{EVF}<\mathrm{SP})_{\mathrm{A}}<\operatorname{Pr}(\mathrm{EVF}<\mathrm{SP})_{\mathrm{B}}$. Thus, in the 
truncated model $\sigma_{\mathrm{v}}$ is identified from the normality assumption and differences in both tails of the error term across a sample of options with different terms.

The preceding discussion describes the data necessary to estimate the parameters of the EVF using data on exercise activity from a single period for two samples of options that have different terms. The data for this study is for exercise decisions over all or part of an 8 year exercise window and we estimate the time until an employee first exercises at least one option from grant $\mathrm{k}$. This is accomplished by dividing the 8 year exercise window into 96 months and estimating discrete time hazard models for the first month in the exercise window that an option from a grant is exercised. The probability an option from grant $\mathrm{k}=1$ to employee " $\mathrm{j}$ " is first exercised in period $\mathrm{M}_{1}$ and an option from grant $\mathrm{k}=2$ is first exercised in period $\mathrm{M}_{2}$ is equal to the probability an option from the first grant is not exercised in periods 1 through $\mathrm{M}_{1}-1$ and then exercised in period $\mathrm{M}_{1}$ and the probability an option from the second grant is not exercised in periods 1 through $\mathrm{M}_{2}-1$ and then exercised in month $\mathrm{M}_{2}$. If $\mathrm{D}_{\mathrm{k}, \mathrm{j}}$ is the month an option from grant $\mathrm{k}$ is first exercised, then this sequence of events occurs with the following probability

(8) $\operatorname{Pr}\left(\mathrm{D}_{1, \mathrm{j}}=\mathrm{M}_{1}, \mathrm{D}_{2, \mathrm{j}}=\mathrm{M}_{2}\right)=\operatorname{Pr}\left[\left(\mathrm{SP}_{1}-\mathrm{EP}_{1, \mathrm{j}, 1}\right)<\mathrm{EVF}_{1, \mathrm{j}, 1},\left(\mathrm{SP}_{2}-\mathrm{EP}_{1, \mathrm{j}, 2}\right)<\mathrm{EVF}_{1, \mathrm{j}, 2}, \ldots . .\left(\mathrm{SP}_{\mathrm{M}-1}-\mathrm{EP}_{\mathrm{k}, \mathrm{j}, \mathrm{Ml} 1-1}\right)<\right.$ $\mathrm{EVF}_{\mathrm{k}, \mathrm{j}, \mathrm{M} 1-1},\left(\mathrm{SP}_{\mathrm{M}}-\mathrm{EP}_{\mathrm{k}, \mathrm{j}, \mathrm{M} 1}\right) \geq \mathrm{EVF}_{\mathrm{k}, \mathrm{j}, \mathrm{M} 1},\left(\mathrm{SP}_{1}-\mathrm{EP}_{2, \mathrm{j}, 1}\right)<\mathrm{EVF}_{2, \mathrm{j}, 1},\left(\mathrm{SP}_{2}-\mathrm{EP}_{2, \mathrm{j}, 2}\right)<\mathrm{EVF}_{2, \mathrm{j}, 2}, \ldots . .\left(\mathrm{SP}_{\mathrm{M} 2-1}-\mathrm{EP}_{2, \mathrm{j}, \mathrm{M} 2-1}\right)$ $\left.<\mathrm{EVF}_{2, \mathrm{j}, \mathrm{M} 2-1},\left(\mathrm{SP}_{\mathrm{M}}-\mathrm{EP}_{2, \mathrm{j}, \mathrm{M} 2}\right) \geq \mathrm{EVF}_{2, \mathrm{j}, \mathrm{M} 2}\right]$

Several adjustments were made to Eq. (8) to account for months when the model is unidentified and nothing can be learned about exercise behavior. In months in the interval $\left[1, \mathrm{M}_{\mathrm{i}}\right]$ when an option is "below water", (e.g., SP-EP < 0), nothing can be learned about the value of holding an option another period because no one will exercise their options at a loss. ${ }^{5}$ Also, in month 96 when options from a grant expire rational employees will always exercise their outstanding options if at that time SP > EP.

Therefore, month 96 is excluded from the likelihood function and the contributions to the likelihood function for grants not exercised in periods 1-95 are treated as right censored in month 95 . The last adjustment was for unexercised options that had not expired by the end of the study period. These grants

\footnotetext{
${ }^{5}$ In our sample the options were always "above water" during the study period so this constraint was never binding.
} 
were also treated as right censored in the last observed time period (i.,e., the last term in $\mathrm{Eq}(8)$ was $\left(\mathrm{SP}_{\mathrm{M}^{-}}\right.$ $\left.\left.\mathrm{EP}_{\mathrm{k}, \mathrm{j}, \mathrm{M}}\right)<\mathrm{EVF}_{\mathrm{k}, \mathrm{j}, \mathrm{M} .}\right)$.

The major methodological issues yet to be discussed are the assumptions made about the structure of the error term in Equation (1) and the related issue of how to estimate the model. First, we assume the error term is normally distributed. If we also assume the v's are normally and independently distributed across option grants, time periods and employees the estimation reduces to an independent Bernoulli model (Heckman 1981a) and Equation (8) equals the product of $\mathrm{M}_{1}+\mathrm{M}_{2}$ individual binary probit functions or:

(9) $\operatorname{Pr}\left(\mathrm{D}_{1, \mathrm{j}}=\mathrm{M}_{1}, \mathrm{D}_{2, \mathrm{j}}=\mathrm{M}_{2}\right)=\operatorname{Pr}\left[\left(\mathrm{SP}_{1}-\mathrm{EP}_{1, \mathrm{j}, 1}\right)<\mathrm{EVF}_{1, \mathrm{j}, 1}\right] \times \operatorname{Pr}\left[\left(\mathrm{SP}_{2}-\mathrm{EP}_{1, \mathrm{j}, 2}\right)<\mathrm{EVF}_{1, \mathrm{j}, 2}\right] \mathrm{x} \ldots$ $\operatorname{Pr}\left[\left(\mathrm{SP}_{\mathrm{M} 1-1}-\mathrm{EP}_{1, \mathrm{j}, \mathrm{M} 1-1}\right)<\mathrm{EVF}_{1, \mathrm{j}, \mathrm{M} 1-1}\right] \times \operatorname{Pr}\left[\left(\mathrm{SP}_{\mathrm{M} 1}-\mathrm{EP}_{1, \mathrm{j}, \mathrm{M} 1}\right) \geq \mathrm{EVF}_{1, \mathrm{j}, \mathrm{M} 1}\right] \times \operatorname{Pr}\left[\left(\mathrm{SP}_{1}-\mathrm{EP}_{2, \mathrm{j}, 1}\right)<\mathrm{EVF}_{2, \mathrm{j}, 1}\right]$ $\mathrm{x} \ldots \ldots . \operatorname{Pr}\left[\left(\mathrm{SP}_{\mathrm{M} 2}-\mathrm{EP}_{2, \mathrm{j}, \mathrm{M} 2}\right) \geq \mathrm{EVF}_{2, \mathrm{j}, \mathrm{M} 2}\right]$

This model is easily estimated by "pooling" the data across option grants, employees and months and then estimating the parameters $\beta$ and $\sigma$ using a standard probit model.

Previous research on modeling state dependence in discrete time processes suggests this specification of the exercise hazard is likely to be incorrect because the error terms each period are correlated across observations (Heckman 1981a). Previous research suggests this correlation reflects, among other factors, unobserved employee risk aversion. More risk averse employees are more likely to have negative values of $v$ or a "low" EVF (conditional on the observables) and seek to "lock-in" options gains by exercising options earlier relative to less risk averse individuals with "large" values of $v$ (Hall \& Murphy, 2002). A positive correlation between the error terms in Eq. (8) across time periods and option grants for an individual will produce biased estimates of the exercise decision process (Heckman 1981b) if this unobserved heterogeneity is not accounted for in the estimation.

A more realistic but still tractable assumption for the error term is a random effects (RE)

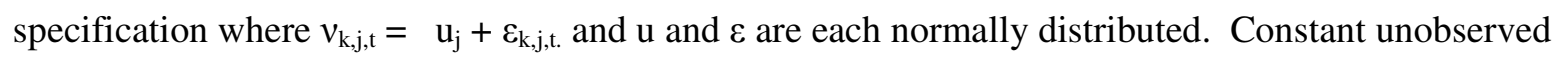
individual effects are captured by $\mathrm{u}_{\mathrm{j}}$ and $\varepsilon_{\mathrm{k}, \mathrm{j}, \mathrm{t}}$ captures purely random factors independent across time periods, individuals and option grants. For an individual, the diagonal elements of the error variance- 
covariance matrix equal $\left(\sigma_{\mathrm{u}}^{2}+\sigma_{\varepsilon}^{2}\right)$, the off-diagonal covariance terms equal $\sigma_{\mathrm{u}}^{2}$, and across individuals the covariance terms are equal to zero. The constant covariance terms for an individual reflects the unobserved individual effects like risk aversion and causes the error terms to have a constant correlation equal to $\sigma_{u}^{2} /\left(\sigma_{u}^{2}+\sigma_{\varepsilon}^{2}\right)$ across time periods and grants for an individual (Heckman, 1981a). To estimate this correlation and control for the constant, unobserved individual heterogeneity requires data for a sample of individuals that receive and exercise option grants on several occasions over the study period. In the firm we study most employees in the sample received options from two grants on two different dates in the early 1990s.

One way of estimating the model that controls for the unobserved individual component is to estimate a fixed effect model that includes a set of dummy variables for each person. While this strategy provides unbiased estimates in a linear model, it does not give consistent estimates for nonlinear models such as a probit model (Heckman 1981b). The alternative to the fixed effect model which does produce consistent estimates is a random effect (RE) probit model (Heckman, 1981a). Since the probability described by Eq. 8 is person j's contribution to the likelihood function, estimating the parameters of the model by MLE requires the integration of an $\mathrm{M}_{1}+\mathrm{M}_{2}$ dimensioned multivariate normal distribution. Good numerical approximations exist for calculating this integral with two or three time periods and for up to, perhaps, 4-5 dimensions, Gaussian quadature procedures produce accurate estimates of the underlying probability (Moffit \& Butler, 1982). ${ }^{6}$ In this study option exercise decisions from a grant can be exercised anytime during the 96 month exercise window and most employees in our sample hold options from two different option grants. Thus, we need to estimate probabilities for a multivariate

\footnotetext{
${ }^{6}$ This is the method used by the xtprobit command in STATA. As the Stata v. 7.0 manual on the xtprobit command notes "The quadrature formula requires that the integrated function be well approximated by a polynomial. If the number of time periods becomes large (as panel size gets large), [the function] is no longer well-approximated by a polynomial." We found the parameter estimates for the unconstrained model produced by the simulated maximum likelihood estimation method described in the next paragraph produced values very close to those given by xtprobit in Stata. However, because the constrained and truncated models could not be estimated using xtprobit we use the simulated maximum likelihood estimates for all of the models so the relative performance of the different models can be compared.
} 
normal distribution with more dimensions than can be feasibly calculated using existing numerical methods.

Research over the last 25 years (Lerman \& Manski 1981, Geweke 1991, Hajivassiliou and McFadden 1990, Keane 1994) and the speed of desktop computers makes simulation estimation methods a feasible way to estimate our model. The GHK (Geweke, Hajivassiliou \& Keane) estimator appears to be the preferred estimator when the error structure is relatively unrestricted. However, the random effects specification permits a simpler and faster simulation method described by Train (2003, chpt 5). ${ }^{7}$ If an analyst could observe $\mathrm{u}_{\mathrm{j}}$, then

(10) $\operatorname{Pr}\left(D_{1, j}=M_{1}, D_{2, j}=M_{2} \mid u_{j}=u_{j}^{*}\right)=$

$$
\begin{aligned}
& \prod_{t=1, M 1}\left(1-I_{1, j, t}\right)\left[1-\Phi\left(\left(\left(S P_{t}-E P_{1, j}\right)-X_{1, j, t} \beta-u_{j}^{*}\right) / \sigma_{\varepsilon}\right)\right]+I_{1, j, t}\left[\Phi\left(\left(\left(S P_{t}-E P_{1, j}\right)-X_{1, j, t} \beta-u_{j}^{*}\right) / \sigma_{\varepsilon}\right)\right] x \\
& \prod_{t=1, M 2}\left(1-I_{2, j, t}\right)\left[1-\Phi\left(\left(\left(S P_{t}-E P_{2, j}\right)-X_{2, j, t} \beta-u_{j}^{*}\right) / \sigma_{\varepsilon}\right)\right]+I_{2, j, t}\left[\Phi\left(\left(\left(S P_{t}-E P_{2, j}\right)-X_{2, j, t} \beta-u_{j}^{*}\right) / \sigma_{\varepsilon}\right)\right]
\end{aligned}
$$

An estimate by simulation of $\operatorname{Pr}\left(D_{1, j}=M_{1}, D_{2, j}=M_{2}\right)$ for a particular value of $\widetilde{\sigma}_{u}$ is obtained by: (a)

creating a $1 \mathrm{x} \mathrm{N}$ matrix of $\mathrm{u}_{\mathrm{j}}$ values randomly drawn from $N\left(0, \tilde{\sigma}_{u}^{2}\right)$, (b) calculating Eq. (10) for each of the $\mathrm{N}$ possible values of $\mathrm{u}_{\mathrm{j}}$ and (c) taking the mean of the $\mathrm{N}$ values from step (b) as an estimate of Eq. (8) (d) repeating steps (a)-(c) for each individual within each iteration of the maximum likelihood routine when an estimate of Eq (8) is required. ${ }^{8}$

For the unconstrained model a "standard" RE probit model was estimated by setting $\sigma_{\varepsilon}=1$ so the coefficient for variable $X_{\mathrm{i}}$ was "standardized" or equal to $-\beta_{\mathrm{i}} / \sigma_{\varepsilon}$, the coefficient on (SP-EP) equals $1 / \sigma_{\varepsilon}$ and the within person correlation between the error terms is $\sigma_{u}^{2} /\left(1+\sigma_{u}^{2}\right)$. Since $\sigma_{\varepsilon}$ is identified in our data because of sample variation in the options' intrinsic value, the unstandardized coefficients $\left(\beta_{\mathrm{i}} \mathrm{s}\right), \sigma^{2}{ }_{\mathrm{u}}$ and

\footnotetext{
${ }^{7}$ See also Guilkey \& Murphy (1993).

${ }^{8} \mathrm{We}$ used an $\mathrm{N}$ of 200 . To improve the performance of the estimation process antithetic draws were made when selecting the $\mathrm{u}_{\mathrm{i}} \mathrm{s}$. Estimating the unconstrained model by simulated maximum likelihood took 5-10 hours of computing time on a $2.4 \mathrm{GHz}$ Pentium 4 single processor computer using Gauss ${ }^{\mathrm{TM}}$ v. 6.00. Estimating the truncated model took about 16 hours. Analytic derivatives of the likelihood function were used in the estimation.
} 
$\sigma_{\varepsilon}^{2}$ were estimated. When the truncated probit model was estimated Eq. (10) was appropriately modified using Eq. $5 .^{9}$

\section{The Data and Empirical Specification}

We have collected a set of very specific information on stock option grants made to a sample of 2180 middle level managers in a large, established firm outside of manufacturing that has many tens of thousands of employees, billions of dollars in sales and locations throughout the United States. ${ }^{10}$ The data we use are from several stock option grant programs where a group of middle level managers were given the opportunity to receive options as part of a stock purchase plan where participants were eligible to receive options proportional to their salary. As discussed above, an important issue required to identify the model is data on options granted at different exercise prices. In our sample employees received options at 13 different exercise prices on 13 different days with the majority of the grants occurring on two calendar dates where one exercise price was almost twice the magnitude of the other exercise price. ${ }^{11}$ We use data on the exercise decisions made by employees for options received in at least the first two grants an employee participated in during the 1990s where the options from the grants had vested before the fall of 2003. Table 1 contains descriptive statistics on the sample of option grants. A total of 3712 options grants were received by the 2180 employees and all but 1127 of these grants were exercised during the study period (e.g., were not right censored). An interesting feature of the experience in this firm is that not all options from a grant were exercised in the same month. In about 58 percent of the option grants where we observe the first exercise date (e.g., the exercise time is not right censored), the employee exercised all of the options in the grant and options exercised on the first exercise day account

\footnotetext{
${ }^{9}$ Because $u_{j}$ represents constant, unobserved individual characteristics, the error truncation in the truncated model cannot occur on $\mathrm{u}_{\mathrm{j}}$ because this would imply the unobserved person effects are not constant from one period to the next. Therefore, we assumed the error truncation was on $\varepsilon$ so that $\operatorname{Pr}\left(D_{1, j}=M_{1}, D_{2, j}=M_{2}\right)$ was calculated by the steps a-d where $\mathrm{u}_{\mathrm{j}}$ was drawn from an untruncated normal distribution.

${ }^{10}$ A condition for obtaining data from the firm included a promise that we would not reveal the identity of the firm. Therefore, we cannot provide a more detailed description of the firm or make the data available to other researchers.

${ }^{11}$ In all cases the options were granted "at the money." That is, the exercise price was equal to the firm's stock price on the day of the grant.
} 
for 77 percent of the total options that could have been exercised. For this reason only the time until the first option from a grant is exercised is examined.

In addition to the terms of each option grant (exercise price, vesting date, expiration date and number of options in the grant), we also have information on the employee's salary and tenure with the firm. A final important feature of the sample is that it excludes managers who joined the firm during the 1990s and managers who received options during the 1990s but left the firm before the Fall of 2003. Thus, this analysis focuses on the exercise decisions of long-tenured, stable employees who were not exercising options in anticipation of leaving the firm. Excluding option recipients who left the firm during the study period simplifies the analysis because we don't have to jointly model turnover and exercise decisions. ${ }^{12}$

Figures $4 \mathrm{a}$ and $4 \mathrm{~b}$ report data on the exercise decisions made by employees in the sample. Figure $4 \mathrm{a}$ is the survival curve for the time to the first exercise date for the 3712 option grants. Twenty-five percent of the grants are exercised by the $34^{\text {th }}$ month following vesting, the median exercise time is 69 months and the $75^{\text {th }}$ percentile of the exercise distribution is 90 months. Figure $4 \mathrm{~b}$ plots the smoothed hazard rate over the first 95 months and shows a relatively stable but low hazard rate during the first 72 months and then a sharp increase in the final year as unexercised options are exercised before they expire. ${ }^{13}$ Over the first 72 months of the exercise window an average of 1.11 percent of unexercised option grants were exercised for the first time in each month.

The exogenous variables in the model determining the EVF fall into three categories; characteristics of the option grant, characteristics of the employee, and financial market indicators that may influence employee exercise decisions. The characteristics of the option include the BSV of the option, BSV squared and cubed, and the number of options the individual received in the option grant.

\footnotetext{
${ }^{12}$ Firms often report that they provide options to improve employee retention. Modeling option exercise decisions and turnover is difficult. While options might reduce turnover, employees that are planning to leave the firm can be expected to exercise vested options before their departure. This creates a positive correlation between exercise decisions and the probability of turnover in the "near term." Modeling exercise decisions and turnover behavior jointly would require a more elaborate competing risk framework and data on employees who did not receive options.

${ }^{13}$ The hazard rate for month 96 is equal to one and is excluded from the smoothed hazard in Figure $4 \mathrm{~b}$.
} 
The closed-form solution for the Black-Scholes value of the option was computed for each month the option was at risk of being exercised using the maximum closing stock price during the month. ${ }^{14}$ The number of shares in the option grant was included to capture the possibility that an employee holding more options may exercise earlier to "lock-in" gains and diversify her wealth.

While the time until the option expires is included in the Black-Scholes formula, Figures 4a and $4 \mathrm{~b}$ suggest time since vesting should be included separately to fully capture the increase in exercise activity as the expiration date approaches. Therefore, the model includes a linear time trend $(\mathrm{T})$ measuring months since the option vested and the following four splines: $\operatorname{Max}(0, T-36), \operatorname{Max}(0, T-48)$, $\operatorname{Max}(0, \mathrm{~T}-60)$ and $(\operatorname{Max}(0, \mathrm{~T}-60))^{2} / 100$. The EVF function also includes a dummy variable equal to " 1 " in the first month the option grant is vested to capture the possibility of a spike in exercise activity caused by the two year vesting period and unobserved individual heterogeneity. For each month an option's intrinsic value and BSV were calculated using the maximum stock price in the month.

The market condition variable included in the EVF was the monthly return to holding a portfolio equal to the Dow Jones Industrial Average and the monthly return for the firm. If employees compare the return to holding stock in the firm with market alternatives, the probability an option is exercised may increase with the return on the overall market (holding the firm's return constant). The individual characteristics in the EVF were the employee's tenure with the firm and the natural log of his/her monthly salary. The tenure variable was calculated each month and the salary variable was adjusted annually to reflect salary changes over the study period. Since the analysis compares the maximum profit that can be made by exercising an option grant in a month with the value an individual places on holding the grant another period for each month over potentially a 10 year period, for each calendar month the (SP-EP), the Black-Scholes value and the employee's salary were converted to real dollars using the CPI.

\footnotetext{
14 The other parameters used to calculate the Black-Scholes value in each month in the exercise window are the usual values - the firm's observed dividend rate, a risk free rate of return equal to the yield on 10 year treasury bonds and the standard deviation of yearly firm returns.
} 


\section{Empirical Results}

Table 2 reports estimates of the parameters of the EVF for different specifications of the unconstrained model of employee exercise decisions. The first three columns report the "standardized" coefficients in the employee value function or $\beta_{\mathrm{i}} / \sigma_{\varepsilon}$. Since the probability an option is exercised equals $\Phi\left((\mathrm{SP}-\mathrm{EP}) / \sigma_{\varepsilon^{-}} \mathrm{X} \beta^{*}\right)$ where $\beta^{*}$ is the vector of "standardized" coefficients in the $\mathrm{EVF}^{15}$, a positive coefficient leads to a predicted increase the EVF in Figure 2 and reduces the probability an option is exercised. The estimates in column 1 report results for a simple specification where the employee value function is a linear function of an option's Black-Scholes value. These estimates imply $\sigma_{\varepsilon}$ equals $\$ 3.91$ $(1 / .2558)$, the unstandardized coefficient on BSV is therefore $0.2314 / 0.2258=\$ 0.90$, the estimated unstandardized intercept term is $2.4387 / 0.2258=\$ 9.53$. In addition $\sigma_{\mathrm{u}}=\$ 1.79$. Constraining the coefficient on BSV to equal one is equivalent to constraining the coefficient on the Black-Scholes variable to be equal to the coefficient on (SP - EP). This constraint is imposed in column 2. A likelihood ratio test comparing the estimates decisively rejects the constraint $(\mathrm{p}<.0001)$ that $\mathrm{E}(\mathrm{EVF})$ changes dollar for dollar with a change in the option's Black-Scholes value.

Back to column (1), the $\$ .90=0.2314 / 0.2258$ increase in an option's value to employees for a dollar increase in the option's BSV is consistent with the prediction that employees value option's at less than the value of equivalent market traded options. However, the large intercept term in the EVF (\$9.53) implies that an option's BSV is less than the option's predicted value to employees. An option with a BSV of \$15-\$20 would be a representative option in the sample and for such an option its predicted value to employees would be $\$ 23$ - $\$ 28$ using the estimates in column 1. Thus, this simple specification suggests employees valued their options at substantially more than the option's BSV.

Column 3 adds the complete set of exogenous variables to the employee value function to produce estimates of the unconstrained EVF model. The estimates in column 3 are the standardized

\footnotetext{
${ }^{15}$ This is a version of equation (3b) where $\beta^{*}=\beta / \sigma$.
} 
EVF coefficients $\left(\beta^{*}\right)$ and column 4 reports the unstandardized coefficients $\beta=\beta^{*} \sigma .{ }^{16}$ Comparing the estimates in column 1 with the estimates in columns 3 or 4 shows the specification with the larger set of variables does a much better job of predicting exercise decisions compared to a model where EVF is only a linear function of the BSV. The difference in the values of the log-likelihood functions between the models in columns 1 and 3 clearly rejects the hypothesis that the coefficients on these additional variables are jointly equal to zero. While the likelihood ratio test favors the more richly specified model, the estimates generated from the model with more covariates yield estimates of $\sigma_{\varepsilon}$ and $\sigma_{\mathrm{u}}$ are 3 to 5 times larger than the estimates in column 1. These results are surprising; as we expected the estimates of $\sigma_{\varepsilon}$ and $\sigma_{\mathrm{u}}$ to decline when additional variables were added to the model. The large estimate of the standard deviation in both unobserved individual heterogeneity $(\$ 10.26)$ and random factors independent across time, options and persons $(\$ 15.28)$ implies many individuals irrationally value their options at an amount substantially greater than the firm's stock price and there are large month to month swings in the EVF for an individual that are independent of the observables in the model.

\section{Comparing the Unconstrained to the Constrained Models}

Table 3 reports the estimates for the constrained model where the coefficient on the option's BSV is constrained to be less than one (column 1) and the model where EVF for each individual is constrained to be less than the firm's stock price (columns $2 \& 3$ ). The estimates that constrain the coefficient on BSV to be less than one are consistent with the estimate in column 1 of Table 2 and show the EVF increases by $\$ .91$ for each dollar increase in an option's BSV. Compared to the more fully specified unconstrained model in Table 2, this constrained model gives more plausible estimates of $\sigma_{\varepsilon}$ and $\sigma_{\mathrm{u}}(\$ 3.42$ and \$2.22). On the other hand, the difference (156.5) between the log-likelihood values between these

\footnotetext{
${ }^{16}$ The coefficients in column 4 are not exactly equal to $\beta^{*} \sigma_{\varepsilon}$ from the estimations in Equation 3 because of slight differences from maximizing the highly nonlinear likelihood functions for the standardized and unstandardized models.
} 
two models shows exercise behavior is better predicted by the model that does not constrain the coefficient on BSV to be less than one. ${ }^{17}$

To compare the three models (unconstrained, constrained so the coefficient on BSV $<1$, constrained so the Employee Value Function is truncated at the stock price) we first examine how well each model predicts the exercise behavior in the data relative to the actual exercise behavior in the sample. This comparison was accomplished by comparing the actual survival curve in the data with the predicted survival curve from each of the models. The predicted survival probability for period $\mathrm{T}$ for individual $\mathrm{j}$ from a model is simply the predicted probability an option had not been exercised by the end of period $\mathrm{T}$ or the probability it was not exercised in period $\mathrm{T}$ given that it had not been exercised in periods 1 through (T-1). Without unobserved heterogeneity, this predicted survival probability is easily calculated for each period and individual in the sample. Deriving the estimated survival probabilities in this study is more complicated because of the unobserved individual heterogeneity in each person's valuation of an option. Estimating the predicted survival probabilities in the presence of unobserved heterogeneity poses the same problem encountered when calculating the exercise probabilities in the likelihood function when estimating the model. Let $\mathrm{S}_{\mathrm{k}, \mathrm{j}, \mathrm{t}}^{\mathrm{m}}$ equal the estimated survival probability for period $\mathrm{t}$ from model $\mathrm{m}$ for an option from grant $\mathrm{k}$ to individual $\mathrm{j}$. The estimated survival probability for period $\mathrm{T}$ in the exercise window equals

$$
\begin{gathered}
S_{k, j, t}^{m}=\operatorname{Pr}\left[\left(S_{1}-E P_{k, j}\right)<X_{k, j, 1} b^{m}+u_{j},\left(S P_{2}-E P_{k, j}\right)<X_{k, j, 2} b^{m}+u_{j},\left(S P_{3}-E P_{k, j}\right)<X_{k, j, 3} b^{m}+u_{j},\right. \\
\left.\ldots . .\left(S P_{T-1}-E P_{k, j}\right)<X_{k, j, T-1} b^{m}+u_{j},\left(S P_{T}-E P_{k, j}\right)<X_{k, j, T} b^{m}+u_{j}\right]
\end{gathered}
$$

If $\mathrm{u}_{\mathrm{j}}$ was observed this equation would simplify to the product of T normally and independently distributed CDFs similar to Eq. 9 and could be easily calculated. Because the $\mathrm{u}_{\mathrm{j}} \mathrm{s}$ are unobserved, a different procedure comparable to the simulation estimation procedure was used to produce the estimated survival probabilities. For each person a random error component, $\tilde{u}_{j}(m)$, was drawn from a $\mathrm{N}\left(0, \sigma_{\mathrm{u}}^{2}(\mathrm{~m})\right)$

\footnotetext{
${ }^{17}$ The model that constrains the coefficient on BSV to be less than one is nested in the unconstrained model in columns 3 and 4 of Table 2 .
} 
distribution where "m" refers to one of our three empirical models, m. The predicted survival probability for period $\mathrm{T}$ conditional on $\mathrm{u}_{\mathrm{j}}=\tilde{u}_{j}$ is

$$
\begin{aligned}
& \left.(11)\left(S_{k, j, T}^{m} \mid \tilde{\mathrm{u}}_{\mathrm{j}}(m)\right)=\operatorname{Pr}\left(\left(S P_{1}-E P_{k, j, 1}\right)<\left(X_{j, i, 1} b^{m}+\tilde{\mathrm{u}} \mathrm{j}(\mathrm{m})\right)\right) x \operatorname{Pr}\left(\left(S P_{2}-E P_{k, j, 2}\right)<X_{j, i, 2} b^{m}+\tilde{\mathrm{u}}_{\mathrm{j}}(m)\right)\right) x \\
& \operatorname{Pr}\left(\left(S P_{3}-E P_{k, j, 3}\right)<\left(X_{j, i, 3} b^{m}+\tilde{\mathrm{u}} \mathrm{j}(\mathrm{m})\right)\right) x \ldots . \operatorname{Pr}\left(\left(S P_{T}-E P_{k, j, T}\right)<\left(X_{j, i, T} b^{m}+\tilde{\mathrm{u}}_{\mathrm{j}}(m)\right)\right)
\end{aligned}
$$

For each randomly drawn value of $\mathrm{u}_{\mathrm{j}}(\mathrm{m})$ survival probabilities were calculated for each period from 1 through $\mathrm{T}$ for an option exercised in period $\mathrm{T}$ by person $\mathrm{j}$. Estimated survival probabilities for each period from 1 to $\mathrm{T}$ were calculated 50 times by drawing 50 different values of $\tilde{u}_{j}(m)$ for each person $\mathrm{j} .{ }^{18}$ The estimated average survival probability for person $\mathrm{j}$, grant $\mathrm{k}$ in period $\mathrm{t}$ is then estimated as the average survival probability over the 50 simulated conditional survival probabilities:

$$
S^{m} k, j, t=(1 / 50) x \sum_{n=1,50}\left(S^{m} k, j, t \mid u_{j}=\tilde{\mathrm{u}}_{\mathrm{n}}\right) .
$$

Since these calculations are done for each of the $\mathrm{T}$ periods, the result is an estimated survival curve for model $\mathrm{m}$ for option $\mathrm{k}$ held by individual $\mathrm{j}$. Estimates of the average survival probability for period 1 through $\mathrm{T}$ were obtained for each person in the sample and for each of the three models. After the estimated survival curves are calculated for each person in the sample, the estimated aggregate sample survival probability for period $t$ was calculated as the mean of $S_{k, j, t}^{m}$ over all subjects who were at risk of exercising their options in period t.

Figures $5 \mathrm{a}-5 \mathrm{c}$ show the estimated survival curves for each model and the actual sample survival curve. Two conclusions follow from this set of figures. First, the model constraining $\beta_{\mathrm{BSV}}<1$ (Figure 5c) does a poor job of predicting exercise activity in the sample compared to the other two models and substantially under-predicts exercise probabilities. Second, the predicted survival curves for the unconstrained and the truncated models (Figures 5a and 5b) closely track each other and the actual sample survival curve. Based on these comparisons and the likelihood ratio test discussed earlier, we conclude

\footnotetext{
${ }^{18}$ There are 2088 distinct individuals in the data and, therefore, $104,400=50 \times 2088$ values of $\mathrm{u}_{\mathrm{j}}$ were randomly selected.
} 
the data are inconsistent with the model that constrains the coefficient on BSV to be less than one and focus the rest of our discussion on the unconstrained and truncated models.

Since the purpose of this analysis is to use exercise activity to identify the dollar value employees place on holding an option, it is important to compare the estimated structural parameters of the EVF for the unconstrained and truncated model in addition to how well each model predicts exercise behavior. This was accomplished by comparing the models' predicted EVF for different but plausible values for exercise times, stock prices and exercise prices. Figures $6 a$ and $6 \mathrm{~b}$ show $\mathrm{E}(\mathrm{EVF} \mid \mathrm{u}=0)$ for an employee with average observable characteristics over the 96 month exercise window for an option with an exercise price of $\$ 5$ and a constant stock price of $\$ 20 .{ }^{19}$ Figure 6a shows the unconstrained model produces estimates of $\mathrm{E}(\mathrm{EVF})$ that far exceeds the firm's stock price of $\$ 20$ over the first 60 months, the predicted EVF then drops sharply in the last three years and in the last 6 months of the option's term the value of holding the option is less than the option's intrinsic value. Also, recall that the estimated value of $\sigma_{u}$ is about $\$ 10$. Therefore, for the 14 percent of the sample with a value of $u_{j}$ greater than $\$ 10$, these estimates imply that at a stock price of $\$ 20$, in month 48 the option is valued by these employees at more than twice the firm's stock price and almost three times the option's intrinsic value. Simply put, the unconstrained model estimates imply widely irrational beliefs by employees. While economic theory predicts no rational valuation of an option can exceed the firm's current stock price, the estimates from this simple empirical model imply that over 84 percent of employees value their option's at more than the firm's stock price. ${ }^{20}$ The valuation implied by the model in the last 6 months of the option's term is equally implausible as it yields valuations substantially less than the option's intrinsic value that could be earned immediately just a few months before the option expires. Finally, the very large estimate of $\sigma_{\varepsilon}(\$ 15)$ implies potentially large random month to month shifts in option valuation around the line shown in Figure 6a for each individual. These results and the fact that the unconstrained model does not take

\footnotetext{
${ }^{19}$ An "average" employee has values of tenure, wages, and options owned equal to the sample averages. A real stock price of $\$ 20$ and an exercise price of $\$ 5$ are close to the average values in the sample.

${ }^{20}$ Figure 6a shows that up to about month 72 the $E(E V F l u=0)$ is at least $\$ 10$ above the firm's stock price. Since the estimated value of $\sigma_{\mathrm{j}}$ is $\$ 10.26,85$ percent have an estimated value of EVF greater than the stock price $(1-\mathrm{F}(-1)=$ .841 .
} 
advantage of an important theoretical prediction, leads us to conclude the unconstrained model of the EVF is implausible.

Figure $6 \mathrm{~b}$ shows estimates of $\mathrm{E}\left(\mathrm{EVF} \mid \mathrm{EVF}<\mathrm{SP}, \mathrm{u}_{\mathrm{j}}=0\right)$ from the truncated model. The econometric specification of this model, which is dictated by the theoretical prediction in finance, must produce predicted values of the EVF that fall below the firm's stock price. Since the data decisively rejected the model that forced $\beta_{\mathrm{BSV}}<1$, the truncated model does not constrain the coefficient on an option's BSV. The portrayal of the estimates in Figure 6b show employees over-value their option's compared to the value of a comparable market traded option. On the option's vesting date the E(EVF) is about $\$ 1.50$ (about 9 percent) more than the option's BSV. Over about the first 84 months of the window the over-valuation increases because the option's BSV declines with the approaching expiration date while the EVF remains basically unchanged. In the final year the EVF declines but remains approximately $\$ 2.00$ greater than the option's BSV and the certain, intrinsic value that could be obtained by exercising the option immediately before it expires. While these estimates do suggest the average option recipient over-values the option's they receive, the estimates do not imply the level of irrationality suggested by the unconstrained model and Figure 6a. Truncating the EVF at the firm's stock price appears to aid in the identification $\sigma_{\mathrm{u}}$ and $\sigma_{\varepsilon}$ and certainly produces much smaller and more plausible values of unobserved constant individual heterogeneity and the period to period random shocks. The estimated value of $\sigma_{\mathrm{u}}(\$ 2.20)$ implies that for the example shown in Figure $6 \mathrm{~b}$ the EVF on the vesting date is less than the option's BSV for a substantial minority (16.5 percent) of the sample. ${ }^{21}$

Figures $7 \mathrm{a}-7 \mathrm{c}$ show additional estimates of the EVF, using the truncated model, where the firm's stock price is allowed to vary and EVF is estimated for months 2, 24, 48 and 94 months. The EVF increases linearly with the firm's stock price and at 24 and 48 months the EVF is $\$ 1$ to $\$ 2$ greater than the option's BSV. By month 94 the EVF is very close to both the option's intrinsic value and BSV.

\footnotetext{
${ }^{21}$ The fraction of employees for which EVF $<$ BSV cannot be analytically derived because of $u_{j}$. If $u_{j}$ is set to zero then the fraction below BSV can be calculated using the CDF of a normal distribution truncated at the stock price. This gives the probability EVF $<$ BSV for an "average" employee but not the probability EVF $<$ BSV averaged over the sample where $u_{j}$ varies. Therefore, the 16.5 percent was calculated from a simulation using a sample of 200,000 draws.
} 
Although it is difficult to see in Figures $7 \mathrm{a}$ and 7b, the difference between EVF and an option's intrinsic value narrows slightly as the stock price increases. Overall, Figures $7 \mathrm{a}-\mathrm{d}$ are consistent with Figure $6 \mathrm{~b}$ and predict employees have overly optimistic beliefs about the value of their options over most of the exercise window.

\section{The Truncated Model Estimates}

Several features of the truncated model estimates other than the results shown in Figures 6 and 7 deserve discussion. The truncated model estimates show significant constant unobserved individual heterogeneity in value of holding an employee stock option. The estimated standard deviation of $u_{i}$ is $\$ 2.20$ and the estimate standard deviation of the error component that is independent across time, grants and individuals is $\$ 2.67$. These parameters yield a within person error correlation of .41 (i.e., $\sigma_{u}^{2} /\left(\sigma_{u}^{2}+\right.$ $\left.\sigma_{\varepsilon}^{2}\right)$ ). This correlation means the exercise probability in one month for an individual is positively correlated with the probability in the next month and that over the two option grants that are available for most of the sample, this positive correlation implies employees who exercised options "early" from their first grant are also likely to be "early" exercisers of options from their second grant for reasons not controlled for by the observables in the model. The significance of these unobserved individual effects highlights the importance of unobserved factors such as employee risk aversion and liquidity constraints that cause individuals to systematically differ in their willingness to hold an option. For example, if risk aversion is one of the important variables in $\mathrm{u}_{\mathrm{j}}$ the estimates imply individuals more risk averse than average will have negative values of $\mathrm{u}_{\mathrm{j}}$ and a greater probability of exercising their option's early in the exercise window. Individuals less risk averse than average will dominate the sub-sample of individuals that hold their options to the end.

One way to illustrate the impact of this unobserved person heterogeneity on the distribution of exercise times is to use the model's estimated parameters to simulate exercise decisions and then compare the values of $u_{j}$ at different exercise times. We first constructed 10,00010 year daily stock price paths based on the historical mean and variance of firm returns. From these daily price paths we constructed 
10,000 monthly stock price paths of the maximum price in each month. Then for each stock price path the exercise decisions of 150 "individuals" was constructed in the following steps. First, for each price path 10 values of $u_{j}$ were randomly drawn from the $\mathrm{N}\left(0, \sigma^{2}{ }_{u}\right)$ distribution. Second, for each value of $u_{j}$ 96 values of $\varepsilon_{\mathrm{j}, \mathrm{t}}$ were drawn from a truncated normal distribution based on $\mathrm{N}\left(0, \sigma_{\varepsilon}\right)$ where the truncation point ensured that $\mathrm{XC}+\mathrm{u}_{\mathrm{j}}+\varepsilon<\mathrm{SP}$. Third, an individual's exercise month was determined by the first month where $\mathrm{XC}+\mathrm{u}_{\mathrm{j}}+\varepsilon_{\mathrm{j}, \mathrm{t}}<(\mathrm{SP}-\mathrm{EP})$. Fourth, for each value of $\mathrm{u}_{\mathrm{j}} 15$ different $(1 \mathrm{x} 96)$ vectors of $\varepsilon_{\mathrm{j}, \mathrm{t}}$ were drawn to produce 150 exercise decisions for each stock price path. This exercise produced 1.5 million $(10,000 \times 15 \times 10)$ exercise decisions.

Figure 8 shows the relationship between $\mathrm{u}_{\mathrm{j}}$ and the exercise month over these simulated decisions. The individual data points in the graph correspond to a one percent random sample of the $\left(\mathrm{u}_{\mathrm{j}}\right.$, Exercise Times) points generated from the simulation and the line in the graph is the OLS regression between the two variables calculated from all the data in the simulation. The regression line shows that when an option first vests the average value of $\mathrm{u}_{\mathrm{j}}$ for exercisers is $\$ 1.60$ below the sample average. By month 94 the average exerciser has a value of $u_{j}$ equal to $\$ .51$. These results have important implications for interpreting Figures $6 \mathrm{~b}$ and 7 where $\mathrm{u}_{\mathrm{j}}$ was held constant at zero. As the expiration date approaches the self-selection on $u_{j}$ means the pool of people that have not yet exercised their options will on average have positive values of $\mathrm{u}_{\mathrm{j}}$ and value options at higher values in the later months than those shown Figures $6 \mathrm{~b}$ and 7.

The one observable individual characteristic that had a statistically significant effect on EVF was the employee's salary (see Table 3). The impact of a change in wages on EVF and the exercise probability was calculated assuming the stock price is $\$ 7.50$ and the exercise price is $\$ 5$ and the month in the exercise window is $48 .^{22}$ A ten percent increase in an average employee's salary increases E(EVF I $\left.\mathrm{EVF}<\mathrm{SP}, \mathrm{u}_{\mathrm{j}}=0\right)$ by $\mathrm{E}(\mathrm{EVF})$ by $\$ .016$ or .25 percent and lowers the exercise probability by 3.7 percent from .0997 to .096 . The positive impact of salary on EVF is consistent with a negative correlation

\footnotetext{
${ }^{22}$ The E $\left(\mathrm{EVF}\right.$ I EVF $\left.<\mathrm{SP}, \mathrm{u}_{\mathrm{j}}=0\right)=\mathrm{XC}-\sigma_{\varepsilon}\left[\left(\mathrm{f}(\mathrm{SP}-\mathrm{XC}) / \sigma_{\varepsilon}\right) /\left(\mathrm{F}(\mathrm{SP}-\mathrm{XC}) / \sigma_{\varepsilon}\right)\right]$ where $\mathrm{f}($.$) and \mathrm{F}($.$) are the pdf and cdf$ of a standard normal variable. The exercise probability is described by Equation (5).
} 
between salary and risk aversion or salary and the presence of a binding household liquidity constraint. We are mildly surprised by this finding in this sample because this is a relatively homogeneous group of middle managers. These estimates imply the exercise behavior of senior managers may be very different from middle managers because of the more substantial salary and wealth differences between executives and middle managers.

Figures $7 \mathrm{a}-7 \mathrm{~d}$ show how the $\mathrm{E}(\mathrm{EVF})$ changes over the exercise window and changes in the firm's stock price. However, these Figures do not show how the exercise probability differs as the stock price moves. Understanding this relationship is important in understanding how much options cost the firm since option costs depend on both the timing and stock price at which employees exercise their options. The earlier discussion of Figure 7 noted the gap between E(EVF) and the option's intrinsic value declines slightly as the stock price increases and in the untruncated model this means the exercise probability increases as this gap declines. However, in the truncated model the exercise probability, which is described by Equation (5), also depends on the gap between the stock price and E(EVF). Since the numerator in Equation (5) increases as the stock price - $E(E V F)$ gap increases which then lowers the exercise probability, it is not obvious from the Figures what the relationship is between the stock price and the exercise probability. One clear thing that could be done is to take the derivative of Equation (5) with respect to the stock price. This, however, gives the change in the exercise probability for only a single period and does not describe how stock price changes alter the exercise time over a 96 month exercise window. Therefore, we examined this relationship by simply plotting the predicted survival curve implied by the parameter estimates for a "high" and "low" stock price path over the 120 month term of an option that vests after 24 months. Based on historical price data for the firm over a 15 year period that included the study period we selected two monthly rates of return (1.5 percent 1.7 percent) that generated ending period stock prices over 120 months that respondents observed over the terms of their options. The predicted survival curves for the two price paths for an average sample member are shown in Figure 9. The exercise pattern for these two price paths are very different; when confronted with the price path with higher returns employees hold onto their options longer and in this example 59 percent of 
the time the option is held until it expires. In contrast when the price path is generated by lower monthly returns employees exercise earlier and 36 percent of the time the option is held until the option expires. These results have important implications for the cost of options to the firm because the firm's costs are positively related to both the length of time employees hold their options and the exercise price (Hall \& Murphy, 2002).

\section{An Alternative Evaluation of Employee Exercise Behavior and Expectations}

The interpretation of the estimates for the different models reported in the preceding section and our preference for the truncated model suggests employees from the studied firm valued options at more than what would be expected if these employees behaved in an economically rational way. The truncated model estimates show that an average employee values employee stock options at less than the option's stock price but greater than the option's Black-Scholes value. We believe there are plausible reasons to believe $\mathrm{E}(\mathrm{EVF})>\mathrm{BSV}$ because employees lack any market signal other than the firm's stock price when evaluating their employee options.

Our results may trouble some readers and raise concerns about both our model and methods. The estimates depend on the validity of a variety of assumptions, the most important of which may be the assumed normality of the two error terms, $\mathrm{u}_{\mathrm{j}}$ and $\varepsilon_{\mathrm{k}, \mathrm{j}, \mathrm{t}}$ and our ability to identify $\sigma_{\mathrm{u}}$ and $\sigma_{\varepsilon}$ from the pattern of exercise decisions. ${ }^{23}$ The assumption that $v_{\mathrm{k}, \mathrm{j}, \mathrm{t}}$ is normally distributed is critical because the structural parameters of the employee value function are identified from the "standardized" probit coefficients only because $\sigma_{\varepsilon}$ is identified from sample variation in the intrinsic value of options, the normality assumption and the constraint that EVF $<$ SP. While we cannot test the validity of these assumptions, there is additional sample evidence that is consistent with the econometric results reported above.

In the dataset the entire exercise history is observed for one of the option grants in which a large number $(\mathrm{N}=1735)$ of employees participates. Out of the 1735 participants in this grant, 318 or 18.3

\footnotetext{
${ }^{23}$ For example, Heckman \& Singer (1986) show hazard model estimates are very sensitive to assumptions made about the unobserved heterogeneity distribution.
} 
percent had not exercised their options at the start of month 94 of the 96 month exercise window. For this option grant the intrinsic value of the option at the start of month 94 was about $\$ 25$ per option. Thus, almost 20 percent of the sample were willing to forego the $\$ 25$ at the start of month 94 in order to capture the expected gain from holding the option for at most 3 more months. What could employees expect to gain over this 3 month period and what does their behavior imply about their risk aversion or their expectations about the firm's future stock price?

Assuming the stock price at the beginning of month 94 equals $\$ 30^{24}$ and the exercise price equals $\$ 5$, the Black-Scholes value of an option expiring in three months is $\$ 25.05$ using reasonable values for the other Black-Scholes parameters. ${ }^{25}$ Thus, a diversified, risk-neutral investor would be willing to hold this option for the remaining three months to collect the expected gain of a nickel or a return of 0.2 percent above what could be earned by immediately exercising the option.

This BSV for an option expiring in 3 months can be compared with the certainty-equivalent dollar value of the option to a risk-averse employee using the Hall and Murphy (2002) methodology. Hall and Murphy assume the utility of " $\$ \mathrm{w}$ " to a risk-averse employee is $\left(\mathrm{w}^{(1-\mathrm{ra})}\right) /(1-\mathrm{ra})$ where ra is the risk aversion parameter. ${ }^{26}$ Using this utility function, they calculate the certain cash payment an executive would have to receive to be indifferent between an immediate cash payment and holding a block of options until the option's expiration date where they assume a substantial portion of the executive's wealth is invested in the firm and their risk aversion parameter equals either 2 or 3 . We apply the Hall and Murphy methodology to our sample but assume employees have none of their non-human capital wealth invested in the firm's stock because they are middle managers. Table 4 shows the certaintyequivalent value of the option at the beginning of month 94 assuming different levels of risk aversion and assuming employees have rational expectations about what will happen to the firm's stock price over the

\footnotetext{
${ }^{24}$ Again, we do not report the actual number since we are unable to disclose the name of the firm.

25 This assumes the short-term risk-free interest rate equals 4 percent/year and the standard deviation of yearly firm returns equals .30 . These numbers are roughly representative of the firm and time period for this option grant.

${ }^{26}$ If $\mathrm{ra}=1$ then $\mathrm{U}(\mathrm{w})=\ln (\mathrm{w})$.
} 
remaining three months of the option's term. ${ }^{27}$ The first column shows the certainty equivalent value of the option before discounting. It is computed by approximating the log-normal price distribution in three months using a binomial price tree with 80 terminal prices. The second column discounts the "month 96 values" in column one to the beginning of month 94 using a 4 percent per year discount rate. At a risk aversion parameter of 2.0, which is the lower bound value Hall and Murphy assume for senior executives, the certainty-equivalent value of the option to an employee is $\$ 0.16$ below ( $\$ 24.84)$ what the employee could get by immediately exercising the option. Any risk aversion parameter greater than 1.60 produces a certainty-equivalent value of less than $\$ 25$.

One of two conclusions can be drawn from Table 4. First, if these employees had unbiased expectations about the firm's future stock price, then none of these employees should have held on to their options past month 93 unless they were significantly less risk averse $(\mathrm{ra}<1.6)$ than the lowest level of risk aversion Hall \& Murphy (2002) use when predicting the behavior of very wealthy senior executives. The other possibility is that these employees had expectations about what would happen to the firm's stock that exceeds the historical average for the firm. With the firm's risk premium of approximately 8 percent and an employee risk aversion parameter of 3.0, an employee would have to believe annual returns were drawn from an annual return distribution centered at 19.5 percent or more to prefer holding the option beyond the end of month 93 and forego the $\$ 25$ that could be earned immediately by exercising the option. Since we have no reason to believe this sample of middle-level managers are significantly less risk averse than executives, these calculations suggest employees had overly optimistic expectations about what would happen to the firm's stock price and cause them to value their options at more than the option's value to an outside investor with rational price expectations. Such

\footnotetext{
${ }^{27}$ By rational expectations about the firm's stock price at the end of month 96 we mean that employees believe returns over the next three months are drawn from a normal distribution centered around a return equal to the risk free return plus a return for market risk that corresponds to the firm's risk premium. On an annual basis we assume a 4 percent risk free return and an 8 percent risk premium.
} 
optimism is consistent with the truncated model estimates that place the employee value function for most employees above the option's BSV. ${ }^{28}$

\section{Summary and Conclusion}

For more than thirty years, economists and others have valued stock options using the pioneering work of Merton (1973) and Black and Scholes (1973). Their techniques are ideal for pricing stock options to diversified investors who are free to trade their options. However, when firms provide stock options to their employees they place limits on how quickly employees can exercise their options in an effort to encourage employees to behave in ways consistent with the interests of shareholders. For this reason, Lambert, Larcker, and Verrecchia (1991) and others have recognized that the value employees place on options may be different from the value placed on options by outside investors. To the best of our knowledge, ours is the first study that uses actual employee exercise behavior to estimate the value employees place on holding employee stock options. We show it is possible to identify the value of options to employees using a simple theoretical model, a discrete time statistical hazard model of exercise behavior and a study design with several key features.

The model that we use is built around the recognition that the prediction from the Black-Scholes model that market traded options will never be exercised prior to their expiration date cannot be used to make a prediction about how employees will behave when deciding when to exercise their untradeable employee stock options. Black-Scholes makes no prediction about how long individuals will own market traded options. It only predicts individuals will sell rather than exercise their options to liquidate their options because the options can always be sold for more than the profit that can be made by exercising them (e.g., BSV $>\max (0$, SP-EP $)$ ). Since employees can't sell their options, exercising their options is their only choice if they wish to profitably dispose of their options. This leads to our model which

\footnotetext{
${ }^{28}$ It is also possible that this could be a type of "loyalty" effect, where employees are expected (by senior management) to hold their options. Given our discussions with managers at this firm, we do not believe this is the case in our situation.
} 
predicts an employee will choose to hold an option for another period if the value from exercising the option is less than the value of holding the option and reserving the right to exercise it at a later date.

The data required to identify and estimate the value to employees of holding an option, the Employee Value Function (EVF), from a hazard model of the option exercise decisions must have two characteristics: (a) the data must include options granted to employees at different exercise prices and expiration dates, and (b) employees in the dataset must receive options from multiple grants. Data condition (a) permits a researcher to separately identify how changes in the benefit from holding the option another period change compared to the gains from immediately exercising the option. These identifying conditions permit us to estimate the $\mathrm{E}(\mathrm{EVF})$, the variance around this expected value and how variation in the EVF and the (Stock price - exercise price) determine when options are exercised.

An important point emphasized in previous research (Lambert, Larcker and Verecchia, 1991, Hall and Murphy, 2003) is that employee exercise decisions are likely to be influenced by risk aversion and household budget constraints. Measures of these theoretically important variables are likely to be absent or very crudely measured in most data (including ours) available to researchers. These data limitations imply the exercise probability in one period for options from one grant for an individual will be correlated with the exercise probabilities for options from a second grant because of the impact of these unobserved individual and household characteristics. Failure to account for this unobserved heterogeneity will produce biased estimates of exercise behavior. Data condition (b), multiple option grants per employees, allows us to estimate the exercise hazard and the EVF and control for unobserved employee heterogeneity that might influence exercise behavior over successive time periods using a random effects probit model that is estimated by simulation methods.

We estimate several models using proprietary data on options granted to over 2000 middle-level managers employed by a large, established firm outside of manufacturing. Our preferred estimates, from a model that truncates the individual's EVF at the firm's stock price, shows the expected value to employees from continuing to hold their options after the vesting date is significantly related to a variety of individual and market characteristics. Options are held longer when the overall stock market is doing 
well relative to the firm's stock price or when an employee has a higher salary. The EVF also closely tracks the firm's stock price and the option's intrinsic value over most of the option's term. We also find exercise decisions are heavily influenced by unobserved employee characteristics which causes a significant (.4) correlation between the value an employee places on options across different option grants. Our estimates are inconsistent with the widely held view that employees value options at less than the option's Black-Scholes value. We find most employees value their options at more than the option's BSV and decisively reject models that constrain the option's value to employees to be less than the option's BSV. The over-optimism of employees suggested by our econometric analysis of exercise decisions is consistent with a simpler analysis of the "end of term" exercise decisions of a significant minority of the sample.

We now turn briefly to a discussion of some of the implications of our results for public policy regulating the information firms are required to disclose about the cost of employee stock options and the information firms should be providing employees about the options they receive. Accounting for stock options has been a topic of considerable discussion for the past decade. In December of 2004 the Financial Accounting Standards Board (FASB, 2004) adopted new standards for how firms report employee stock options as an expense at the time the options are granted. The new rules require that firms use Black-Scholes or a "Black-Scholes-like" formula to expense options and encourages firms to include in their cost estimates the expected exercise pattern of employees because this pattern affects the cost of options to the firm. Firms are encouraged to look at the past exercise decisions of employees when determining the expected exercise pattern for newly granted options. This study shows how a firm might analyze employee exercise behavior which might then be used as an input in forecasting the cost of new employee option grants.

Our finding that options in this firm were valued by employees at a level above the Black-Scholes value suggests the value of these options to employees is greater than the cost of the options to the firm since "early" exercise decisions by employees implies option costs that are less than the firm's BlackScholes value. Thus, if this firm were to decide to curtail the use of options for middle managers because 
of the new FASB rule, it would likely lead to employee dissatisfaction that could, perhaps, be offset only by paying employees more than what the firm is spending on options. In this firm these options appear to be a source of firm "competitive advantage." This firm and other firms that offer ESO may do so precisely because their employees are overly optimistic about the firm's future.

Although the theory and empirical methods in this paper are completely general, the estimates describe the behavior of a specific set of employees, during a particular time period in one firm. Whether the estimates reported here generalize to other firms, employees and time periods can only be determined by extending the analysis to other samples. For example, do executives value options differently from non-executives? We also intend to explore a number of other issues using the data from the current firm. These issues include estimating models that permit a more general error structure in the EVF equation, estimating state dependence in exercise activity and a comparison of the discrete-time probit hazard estimates with estimates from more traditional continuous time hazard models. This study focuses solely on the first exercise date for options from a grant. In about half of the first exercise decisions less than 100 percent of the options in the grant are exercised. This implies options from a grant are not equally valued and something could be learned about the value of options to employees by studying the partial/complete exercise decision of employees and the timing of the second exercise decision when less than 100 percent of the options are exercised on the first exercise date. The options employees received that are used in this study were part of an employee stock purchase plan. This allows us to estimate another value for EVF using the decisions made by employees to participate in the plan. These estimates can then be compared with the values reported here or a model of both the probability of participating and the Pr(exercisingl participation) can be estimated simultaneously. Finally, we hope to obtain additional data from the firm that will allow us to investigate whether employees value options differently based on different demographic characteristics (gender, age, marital status, geographic location). A great deal more work can be done to better understand the value of stock options to employees. We think this study is a useful step along this path. 


\section{References}

Ashenfelter, Orley and David E. Bloom, 1984, "Models of Arbitrator Behavior," American Economic Review, 74, 111-124.

Bergman, Nittai K., and Dirk Jenter, 2004, "Employee Sentiment and Stock Option Compensation," working paper, MIT.

Black, Fisher, and Myron Scholes, 1973, "The Pricing of Options and Corporate Liabilities," Journal of Political Economy, May-June, 637-654.

Brealey, Richard A., Stewart C. Myers \& Alan J. Marcus, 1995. Fundamentals of Corporate Finance. McGraw-Hill, Inc.: New York.

Carpenter, Jennifer, 1998, "The Exercise and Valuation of Executive Stock Options," Journal of Financial Economics, 48, 127-158.

Core, John, and Wayne Guay, 2001, "Stock Option Plans for Non-Executive Employees," Journal of Financial Economics, 60, 253-267.

Financial Accounting Standards Board, "Exposure Draft of Proposed Statement on Financial Standards, Share-Based Payment: An Amendment to FASB Statements No. 123 and 95," Norwalk, CT: FASB, March 31, 2004, www.fasb.org.

Geweke, John, 1991, "Efficient Simulation from the Multivariate Normal and Student-t Distribution Subject to Linear Constraints," in Computing Science and Statistics: Proceedings of the $23^{\text {rd }}$ Symposium on the Interface, Alexandria, VA: American Statistical Association, 571-78.

Guilkey, David K., and James L. Murphy, 1993, "Estimation and Testing in the Random Effects Probit Model," Journal of Econometrics, 59, 301-317.

Hall, Brian, and Jeffrey Liebman, 1998, “Are CEOs Really Paid Like Bureaucrats?,” Quarterly Journal of Economics 132(3), 653-692.

Hall, Brian, J. and Kevin J. Murphy, 2002, "Stock Options for Undiversified Executives," Journal of Accounting and Economics, 33, 3-42.

Hall, Brian, J. and Kevin J. Murphy, 2000, "Optimal Exercise Prices for Executive Stock Options," Papers and Proceedings of the One Hundred and Twelfth Meeting of the American Economic Association," May 209-214.

Hall, Brian J., and Kevin J. Murphy, 2003, “The Trouble with Stock Options," Journal of Economic Perspectives, 17, 49-70.

Hajivassiliou, V.A, and Daniel L. McFadden, 1990, "The Method of Simulated Scores for the Estimation of LDV Models with an Application to External Debt Crisis," Cowles Foundation, Yale.

Heath, Chip, Steven Huddart, and Mark Lang, 1999, "Psychological Factors and Stock Option Exercise," Quarterly Journal of Economics, 114(2), May, 601-27. 
Huddart, Steven, and Mark Lang, 1996, "Employee Stock Option Exercises: An Empirical Analysis," Journal of Accounting and Economics, 21(1), February, 5-43.

Heckman, James J., 1981a, "Statistical Models for Discrete Panel Data," in Structural Analysis of Discrete Data with Econometric Applications, edited by Charles F. Manski and Daniel McFadden, MIT Press: Cambridge.

Heckman, James J., 1981b "The Incidental Parameters Problem and the Problem $\mathrm{f}$ Initial Conditions in Estmating a Discrete Time-Discrete Data Stochastic Process," in Structural Analysis of Discrete Data with Econometric Applications, edited by Charles F. Manski and Daniel McFadden, MIT Press: Cambridge.

Heckman, James J., 1979, "Sample Selection Bias as a Specification Error," Econometrica, 47(1), February, 153-161.

Hull, John C., 2003, Options, Futures, and Other Derivatives, Prentice-Hall, Englewood Cliffs, New Jersey.

Kahneman, Daniel, and Amos Tversky, 1979, "Prospect Theory: An Analysis of Decisions Under Risk," Economterica, 47, 313-327.

Keane, Michael P., 1994, "A Computationally Efficient Practical Simulation Estimator for Panel Data," Econometrica, 62, 95-116.

Kedia, Simi, and Abon Mozumdar, 2002, "Perform,ance Impact of Emnloyee Stock Options," Working Paper, Harvard University, and Virginia Tech.

Lambert, Richard A., David F. Larcker, and Robert E. Verecchia, 1991, "Portfolio Considerations in Valuing Executive Compensation,” Journal of Accounting Research, 29, 129-149.

Lerman, Steven R. \& Charles F. Manski, 1981, "On the Use of Simulated Frequencies to Approximate Choice Probabilities," in Structural Analysis of Discrete Data with Econometric Applications, edited by Charles F. Manski and Daniel McFadden, MIT Press: Cambridge.

Merton, Robert C., 1973, "The Theory of Rational Option Pricing," Bell Journal of Economics and Management Science, 4, Spring, 141-183.

Moffit, Robert and J.S. Butler, 1982, “A Computationally Efficient Quadrature Procedure for the OneFactor Multinomial Probit Model,” Econometrica, 50, 761-764 \& 1596.

Murphy, Kevin J., 1999, "Executive Compensation," in Handbook of Labor Economics, Volume 3, Orley Ashenfelter and David Card, editors, North Holland.

Olson, Craig A. and Paul Jarley, 1991, "Arbitrator Decisions in Wisconsin Teacher Wage Disputes," Industrial and Labor Relations Review, 536-547.

Oyer, Paul, and Scott Schaefer, 2004a, "Why Do Some Firms Give Stock Options to All Employees? An Empirical Examination of Alternative Theories," Journal of Financial Economics, forthcoming.

Oyer, Paul, and Scott Schaefer, 2004b, "Accounting, Governance, and Broad-Based Stock Options Grants," working papers Stanford University and Northwestern University. 
Train, Kenneth E., 2003, Discrete Choice Methods with Simulation, Cambridge: Cambridge University Press.

Vuong, Quang, H., 1989, "Likelihood Ratio Tests for Model Selection and Non-Nested Hypotheses,"Econometrica, 57, 307-333. 
Figure 1

\section{Black-Scholes and Intrinsic Value of A Call Option}






\section{Figure 2}

\section{Black-Scholes Value and The Value of An Option To An Employee (Employee Value Function)}




Figure 3

\section{The Exercise Probability In The Model Where The EVF is Truncated At The SP}



Stock Price 
Figure 4a

Sample Exercise Activity

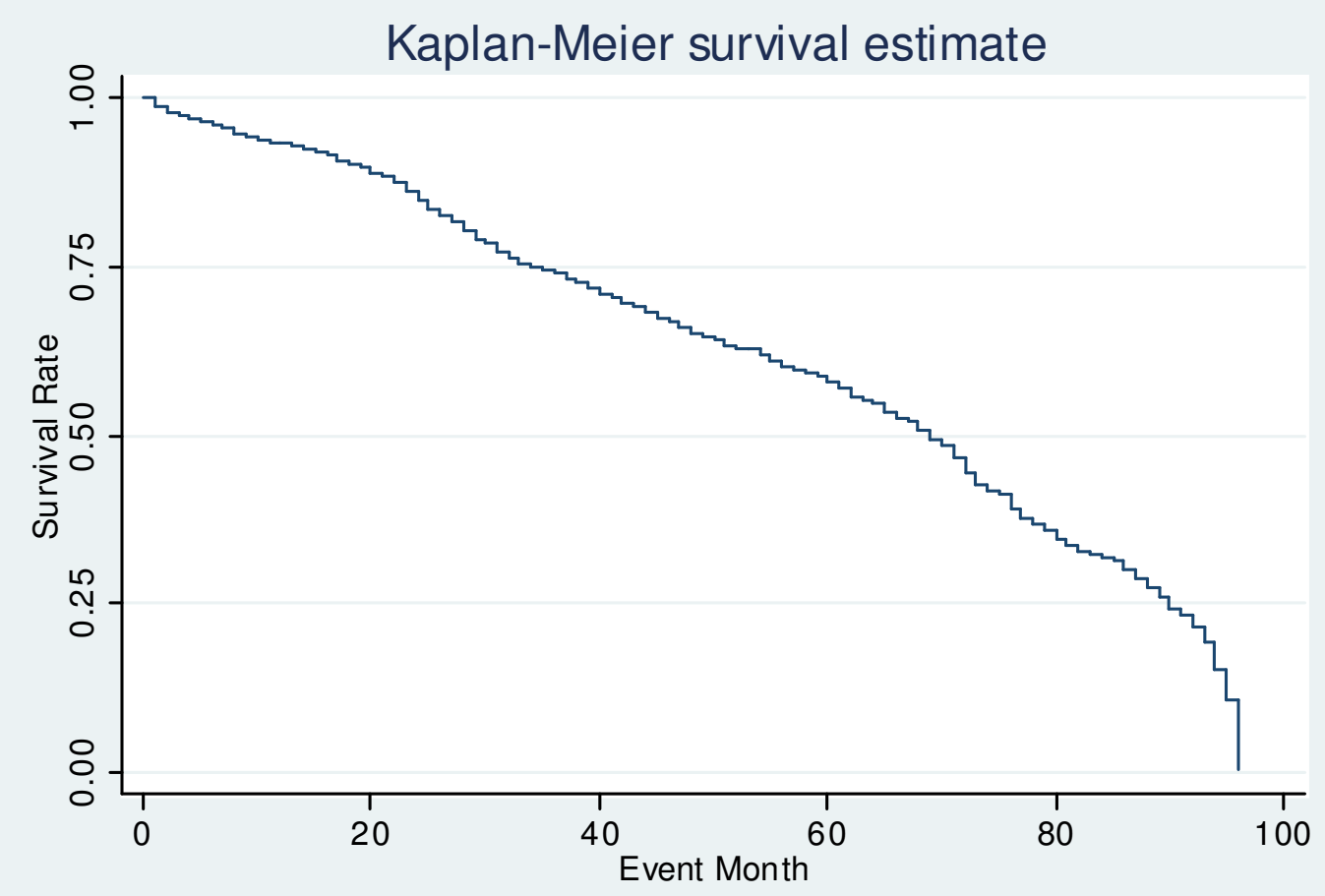

hazsurv. do 11/2/05

Figure $4 \mathrm{~b}$

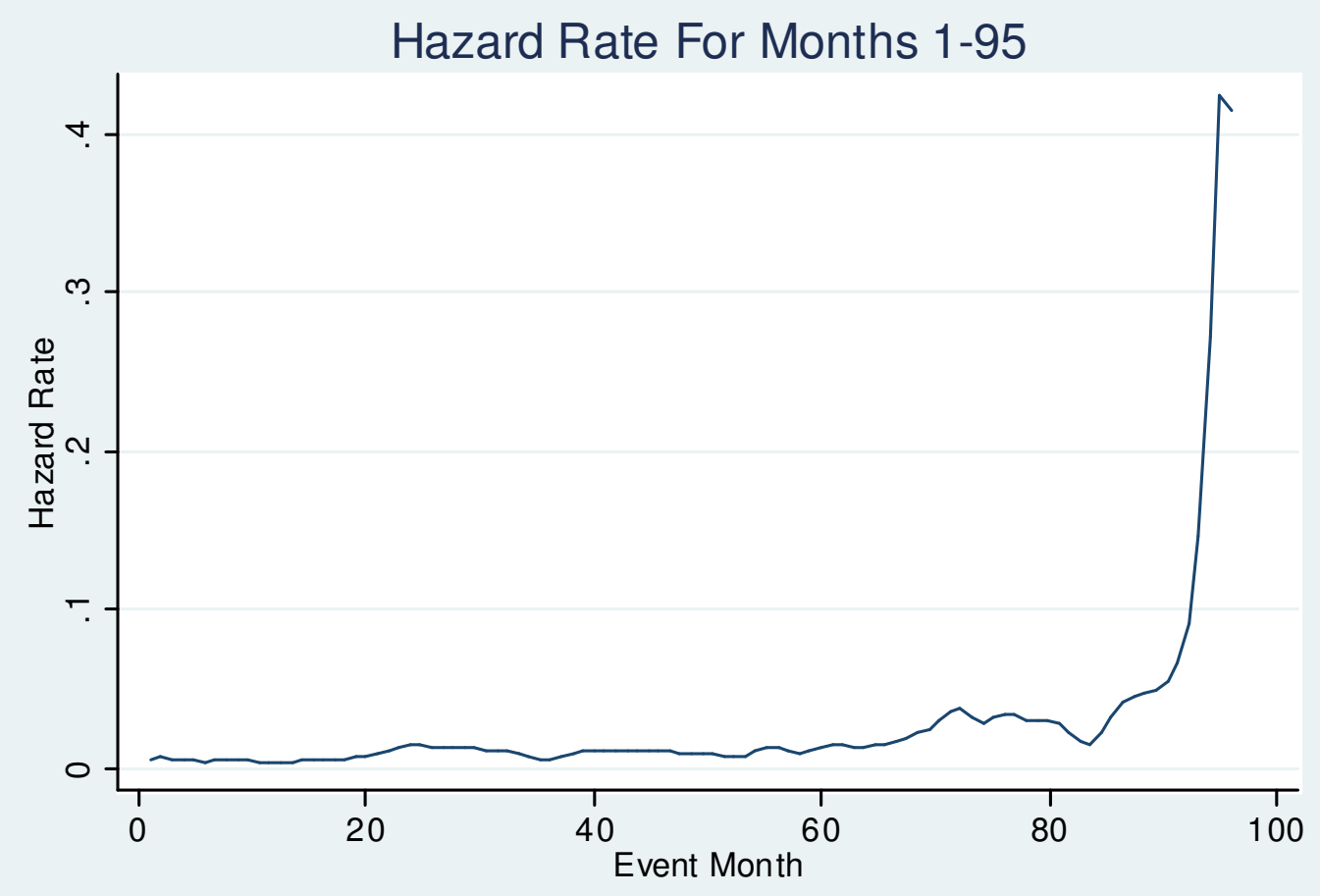

hazsurv.do 11/2/05 


\section{Figure 5 a}

\section{Model Fit}

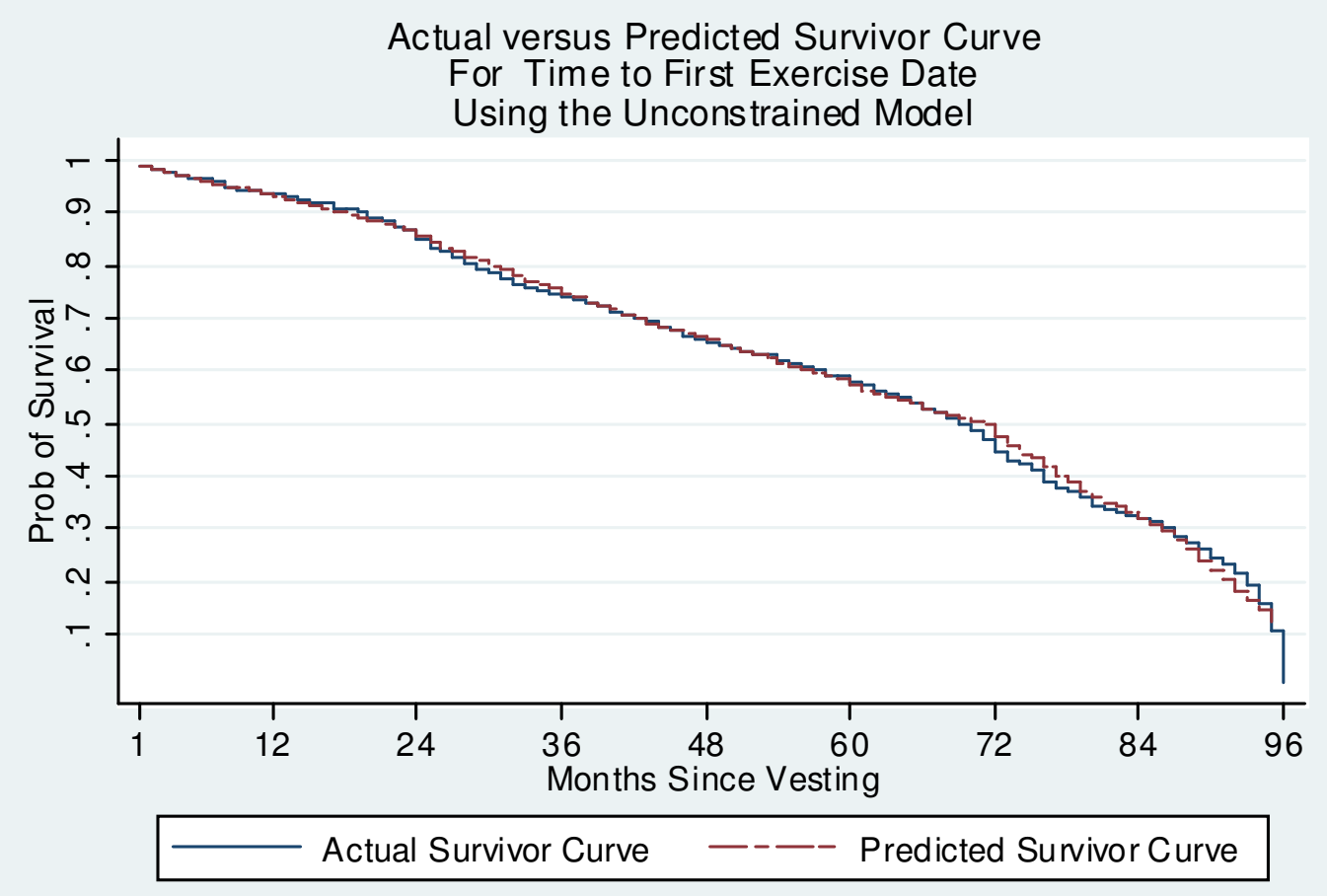

modelfit_unconstrained 10/31/05.

Figure 5 b

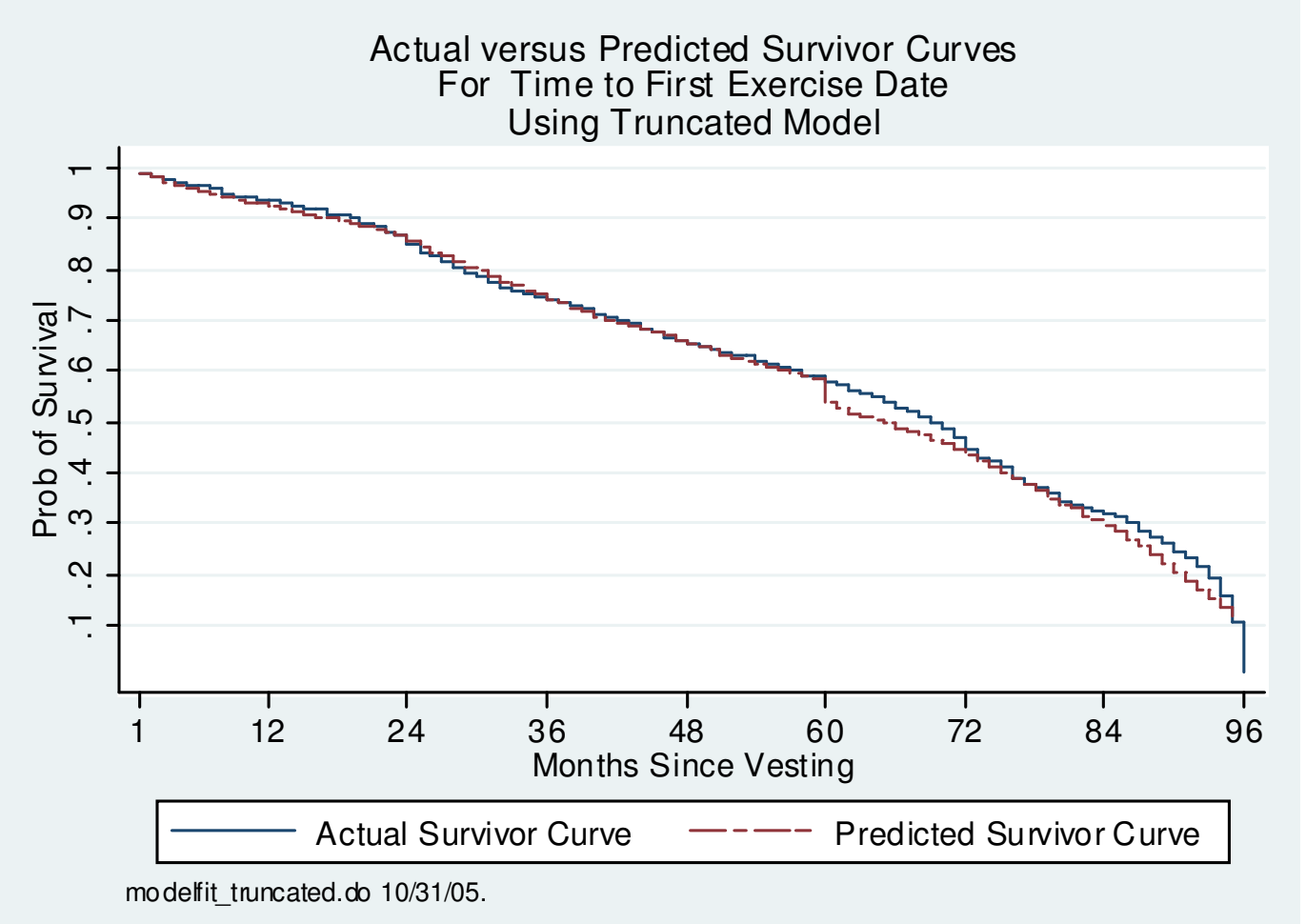


Figure $5 \mathrm{c}$

\section{Model Fit (Continue)}



Notes: 


\section{Figure 6 a}

\section{Estimated EVF}

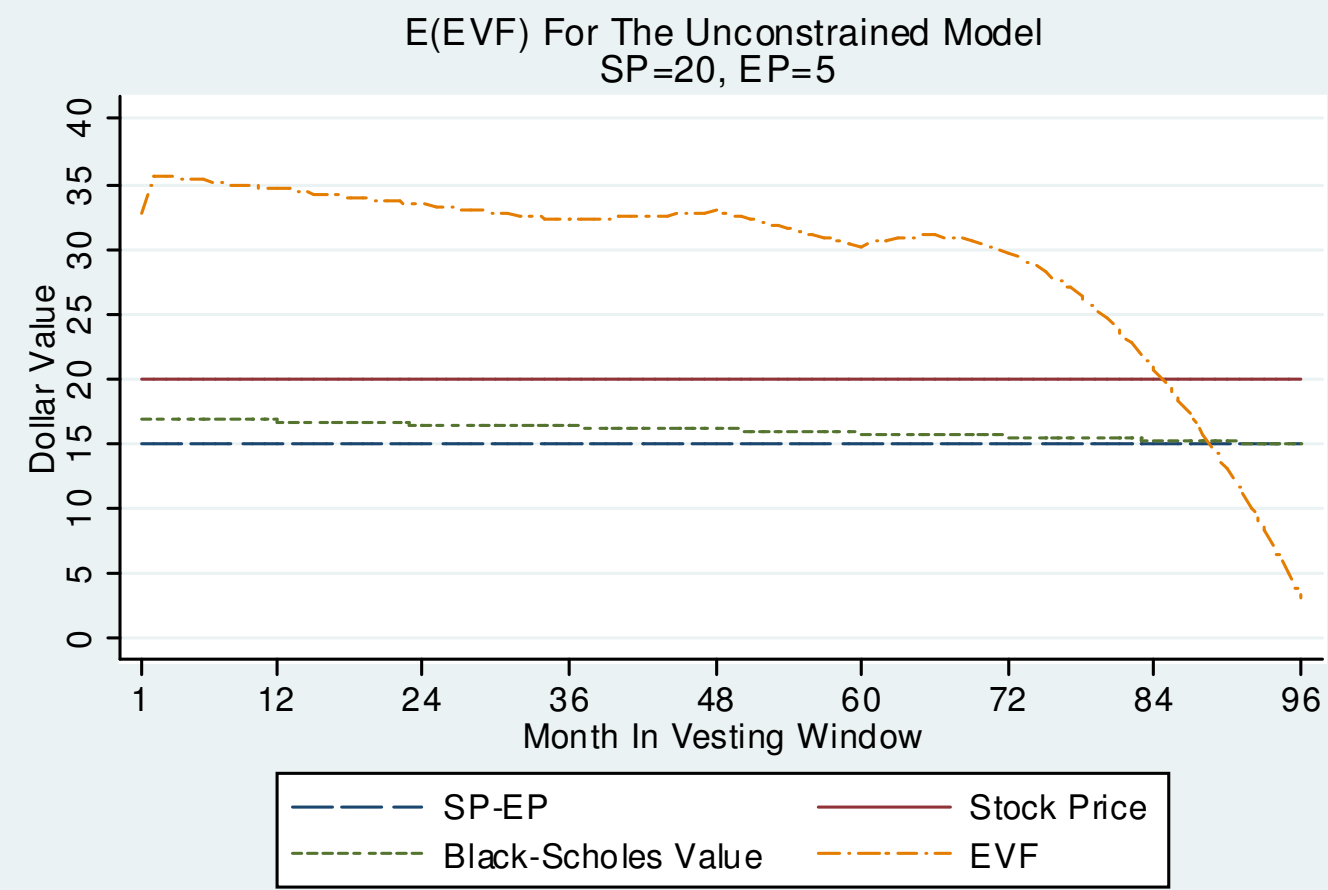

evf_unconstrained.do 10/31/05.

Figure 6 b



cigraphs2.do 11/4/05 


\section{Figure 7a}

\section{Estimated EVF For Truncated Model}



Figure 7b

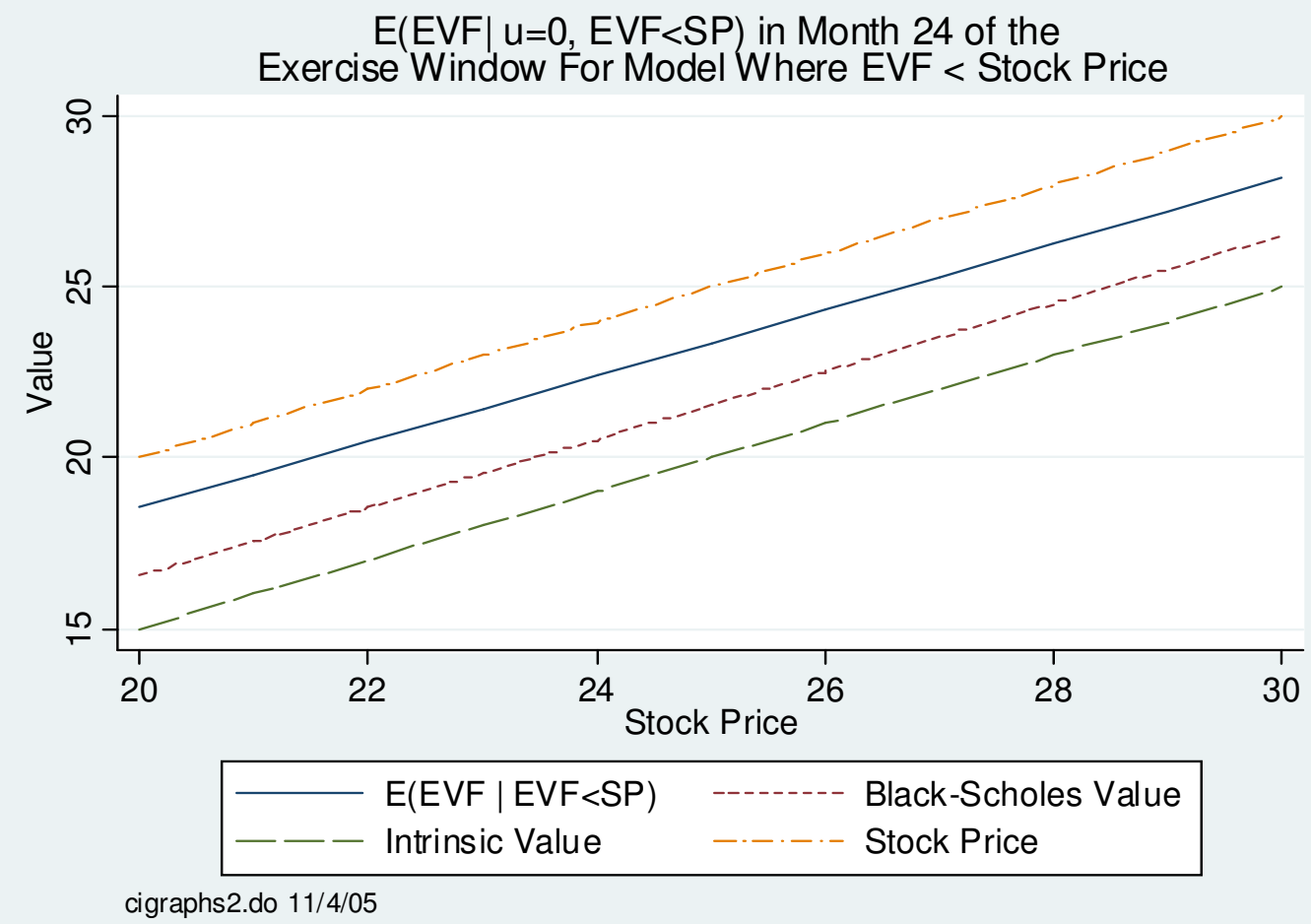




\section{Figure 7c}

\section{Estimated EVF For Truncated Model (Continue)}

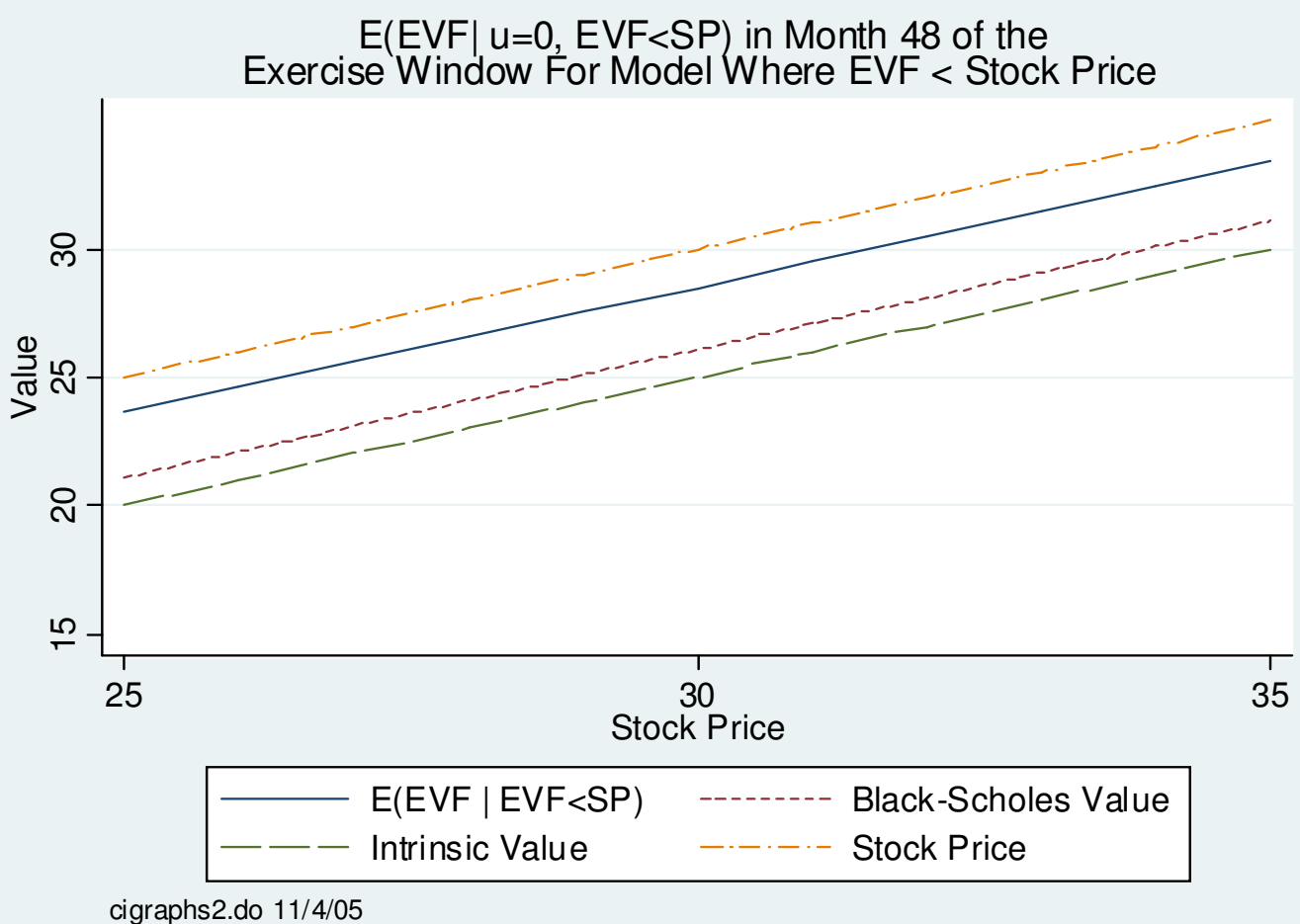

Figure 7d

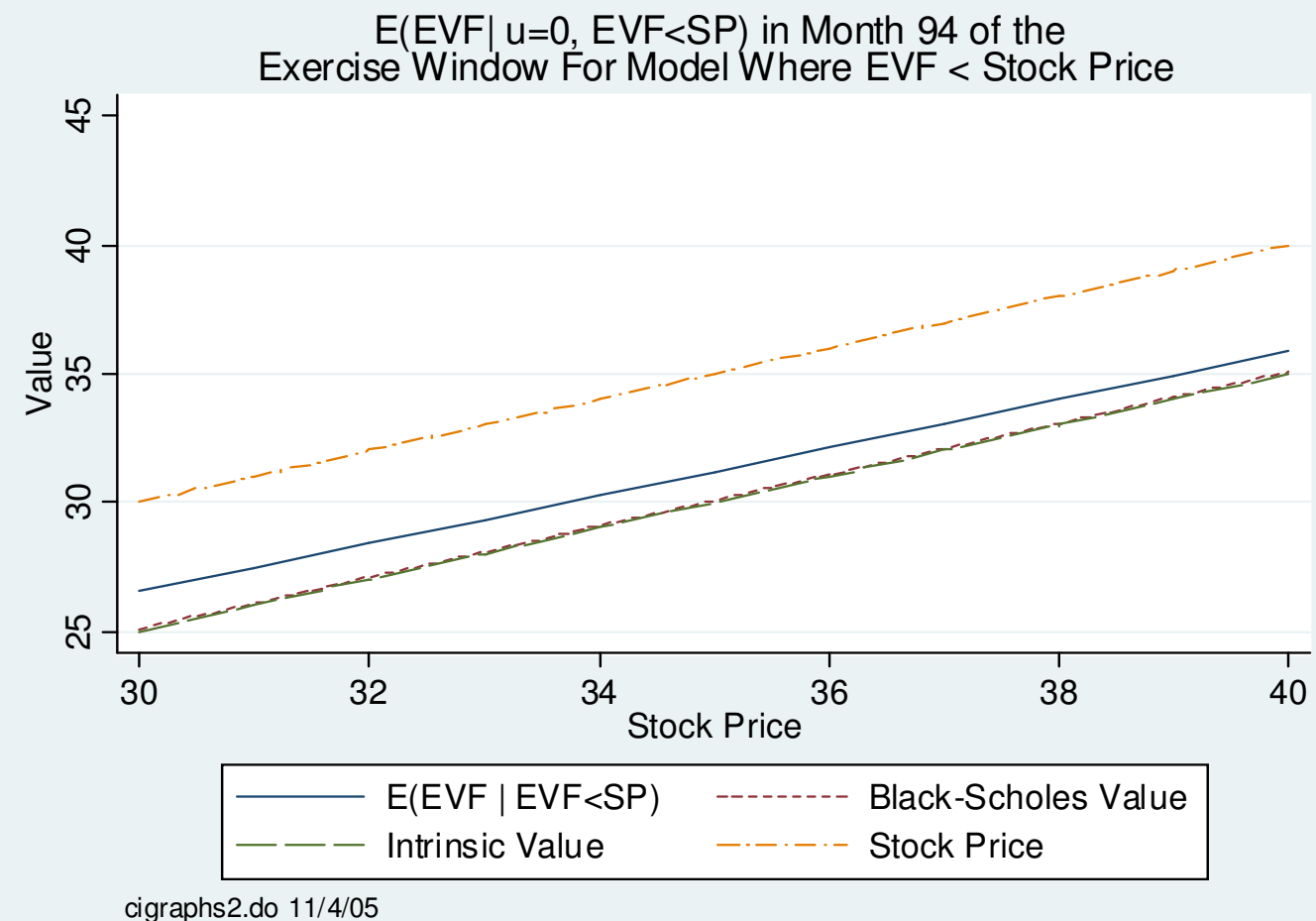




\section{Figure 8}

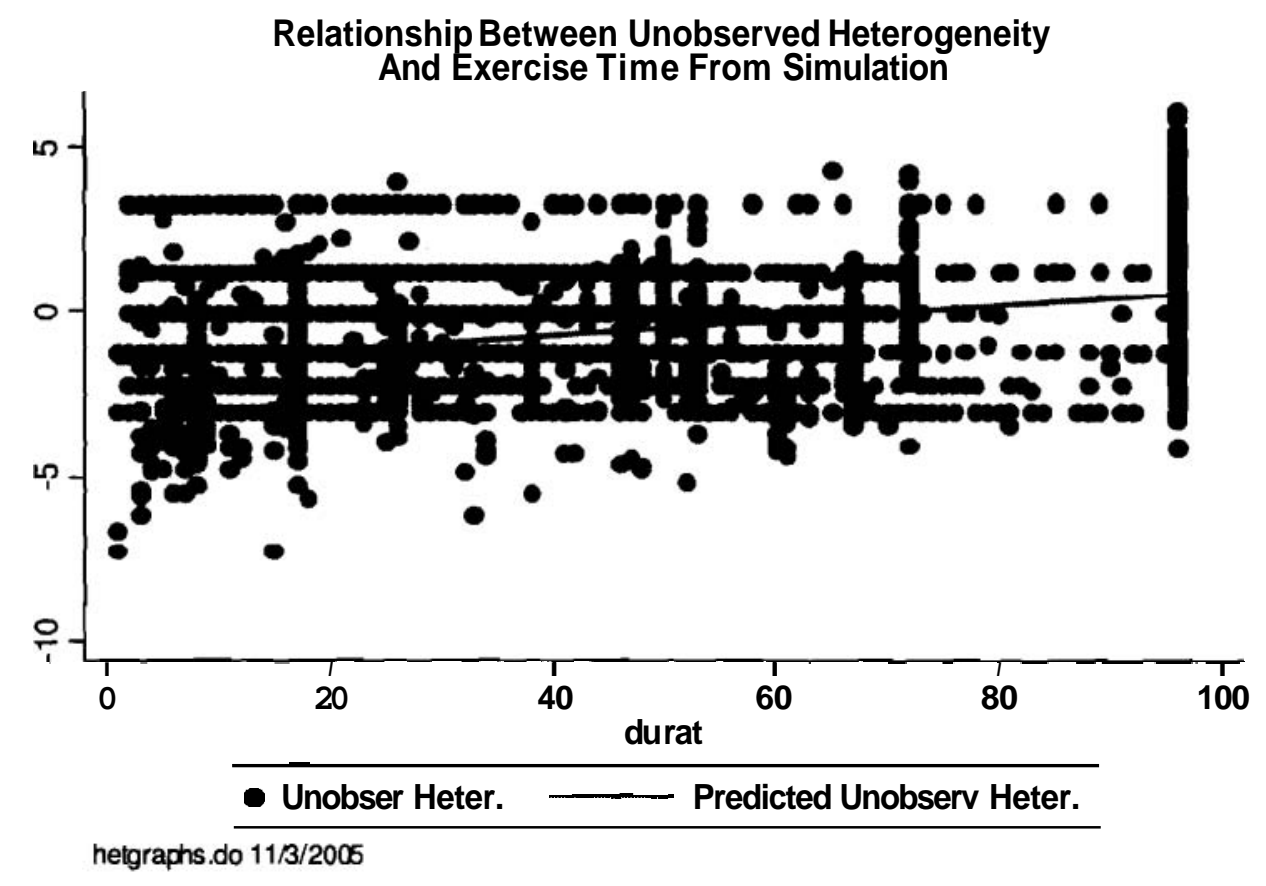

Line: $-1.6417+.02289$ (durat) 


\section{Figure 9}




Table 1

Summary Statistics on Exercise Decisions

$\begin{array}{ll}\text { Number of Employees Receiving Options } & 2180\end{array}$

$\begin{array}{ll}\text { Number of Option Grants } & 3712\end{array}$

$\begin{array}{lr}\text { Number of option grants where time to } & 1127\end{array}$

first exercise date is censored

$\begin{array}{ll}\text { Mean options/grant } & 1302\end{array}$

$\begin{array}{ll}\text { Mean hazard rate/month } & 0.0128\end{array}$

25th Percentile of Time to 1st exercise date (months) 34

Median time to first exercise date (months) 69

75th Percentile of Time to 1st exercise date (months) 90

$\begin{array}{ll}\text { Options exercised on first exercise date } & 0.765\end{array}$

as fraction of options in the grant

$\begin{array}{ll}\text { Fraction of first exercise decisions where } & 0.576\end{array}$

$100 \%$ of options in grant were exercised 
Table 2

Unconstrained Estimates of The Exercise Hazard Rate and Employee Value Function

(SE in parentheses)

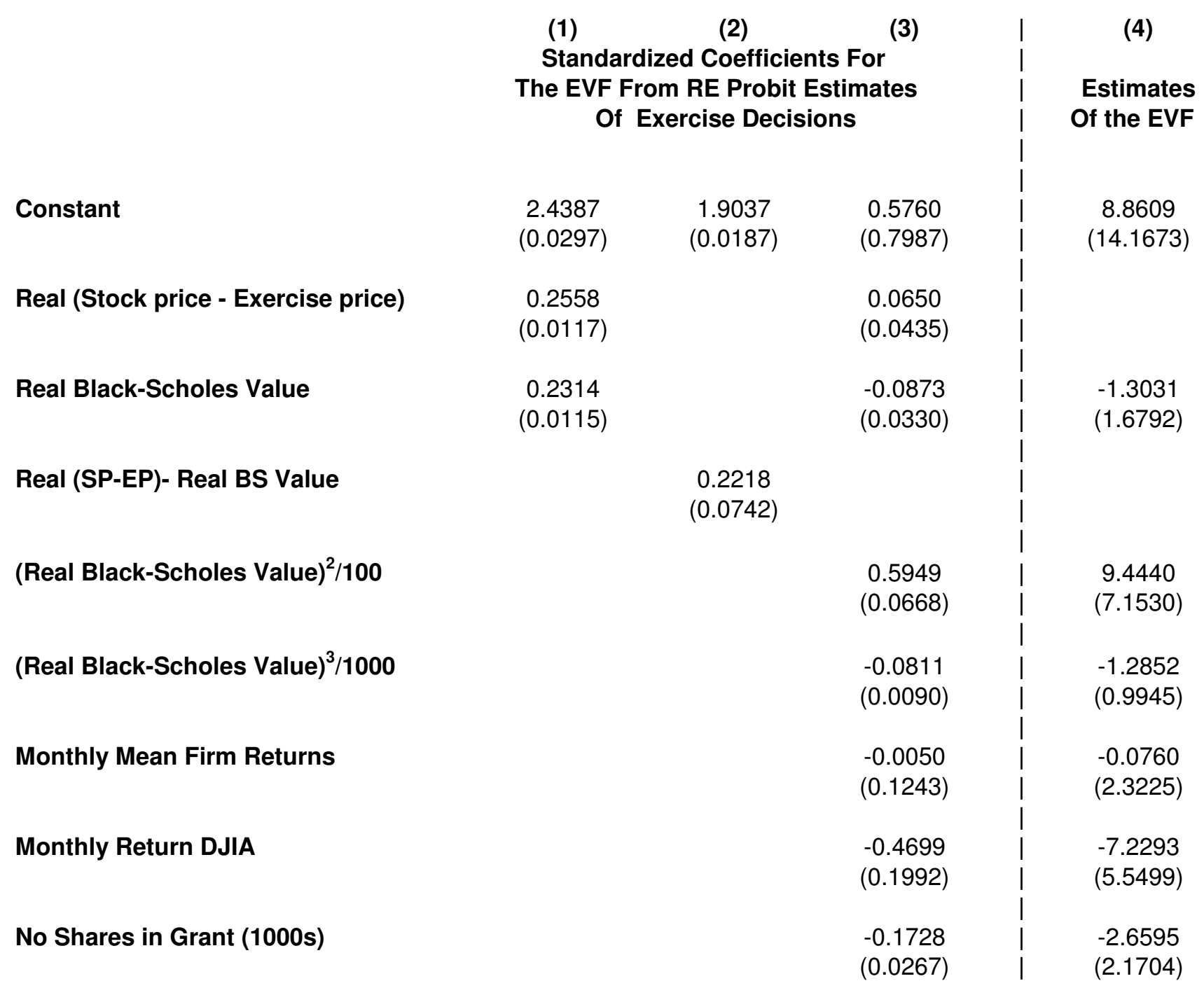


Table 2 (Continue)

Ln(Real Monthly Wage)

Firm Tenure (Years)/100

$=1$ if first month options are vested

Months Since Vested

$\operatorname{Max}(0$, Months Since Vested-36)

$\operatorname{Max}(0$, Months Since Vested-48)

Max(0,Months Since Vested-60)

$\operatorname{Max}(0, \text { Months Since Vested- } 60)^{2} / 100$

$\sigma(\varepsilon)$ (error iid time, person grants)

$\sigma(u)$ (fixed individual random error)

$11 / 5 / 2005$




Table 3

Constrained Estimates of The Exercise Hazard Rate and Employee Value Function

(SE in parentheses)

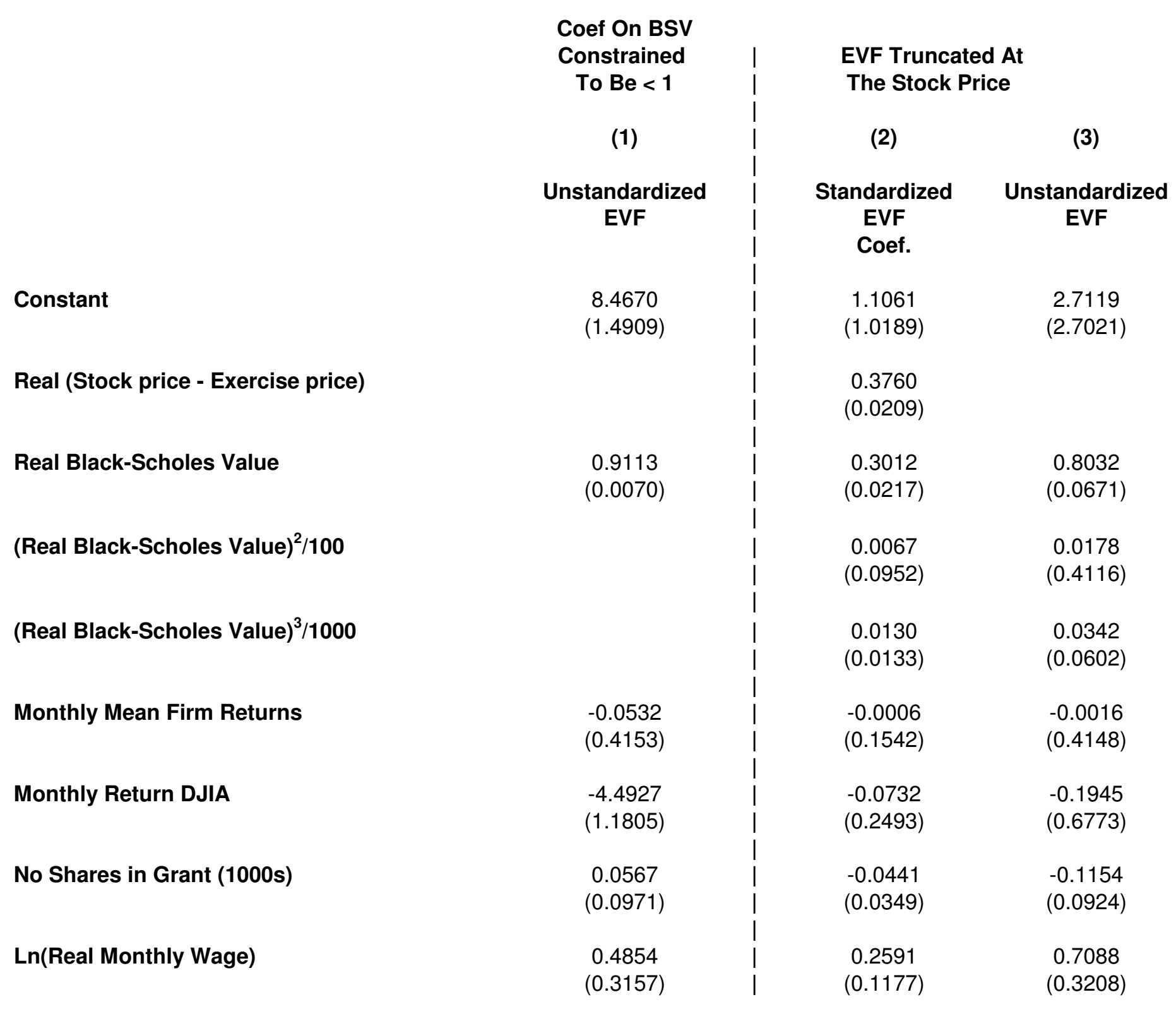


Table 3 (Continue)

Firm Tenure (Years)/100

$=1$ if first month options are vested

Months Since Vested

0.0041

(0.2583)

$\operatorname{Max}(0$, Months Since Vested-36)

\section{Max(0,Months Since Vested-60)}

\subsection{8}

(0.0348)

$\operatorname{Max}(0, \text { Months Since Vested-60 })^{2}$

$\sigma(\varepsilon)$ (error iid time, person grants)

$\sigma(u)$ (fixed individual random error)

$11 / 5 / 2005$ 


\section{Table 4}

\section{Values Of A 3 Month Option With An Exercise Price}

Of $\$ 5$ And A Current Stock Price Of $\$ 30$

$\begin{array}{ccc} & \begin{array}{c}\text { E(U(SP-EP) } \\ \text { Assuming No } \\ \text { Discounting }\end{array} & \begin{array}{r}\text { E(U(SP-EP)) } \\ \text { Discounted } \\ \text { At Risk-Free } \\ \text { Interest Rate }\end{array} \\ \begin{array}{c}\text { Black-Scholes Value } \\ \text { Risk Aversion } \\ \text { Parameter }\end{array} & \$ 25.30 & \$ 25.05 \\ \text { Risk-Neutral } & \text { Certainty-Equivalent Values } \\ 1.0 & \$ 25.91 & \\ 1.5 & \$ 25.50 & \$ 25.66 \\ 2.0 & \$ 25.29 & \$ 25.25 \\ 2.5 & \$ 25.09 & \$ 25.05 \\ 3.0 & \$ 24.88 & \$ 24.84 \\ 3.5 & \$ 24.68 & \$ 24.64 \\ & \$ 24.47 & \$ 24.44\end{array}$

1. $U(x)=W^{(1-r a)} /(1-r a)$ for $r a \neq 1$ and $U(x)=\ln (x)$ for $r a=1$.

The risk neutral interest rate is 4 percent, the firm's risk premium is 8 percent and the standard deviation of firm returns is 30 . 